\title{
Heterogeneous microstructure and enhanced mechanical properties in annealed multilayered IF steel
}

Jiang, Xiaojuan; Zhang, Lijuan; Zhang, Ling; Huang, Tianlin; Wu, Guilin; Huang, Xiaoxu; Mishin, Oleg V.

Published in:

Materials Science and Engineering A

Link to article, DOI:

10.1016/j.msea.2019.05.034

Publication date:

2019

Document Version

Peer reviewed version

Link back to DTU Orbit

Citation (APA):

Jiang, X., Zhang, L., Zhang, L., Huang, T., Wu, G., Huang, X., \& Mishin, O. V. (2019). Heterogeneous microstructure and enhanced mechanical properties in annealed multilayered IF steel. Materials Science and Engineering A, 759, 262-271. https://doi.org/10.1016/..msea.2019.05.034

\section{General rights}

Copyright and moral rights for the publications made accessible in the public portal are retained by the authors and/or other copyright owners and it is a condition of accessing publications that users recognise and abide by the legal requirements associated with these rights.

- Users may download and print one copy of any publication from the public portal for the purpose of private study or research.

- You may not further distribute the material or use it for any profit-making activity or commercial gain

- You may freely distribute the URL identifying the publication in the public portal 


\title{
Heterogeneous microstructure and enhanced mechanical properties in annealed multilayered IF steel
}

\author{
Xiaojuan Jiang ${ }^{1}$, Lijuan Zhang ${ }^{1}$, Ling Zhang ${ }^{1, *}$, Tianlin Huang ${ }^{1}$, Guilin $\mathrm{Wu}^{1}$, \\ Xiaoxu Huang ${ }^{1,2}$, Oleg V. Mishin ${ }^{1,2, * *}$ \\ ${ }^{1}$ Joint International Laboratory for Light Alloys (MOE), College of Materials Science and Engineering, \\ Chongqing University, Chongqing, 400045, China \\ ${ }^{2}$ Department of Mechanical Engineering, Technical University of Denmark, 2800 Kgs. Lyngby, \\ Denmark
}

\begin{abstract}
The microstructure and mechanical properties have been studied in interstitial free (IF) steel samples consisting of compression-bonded alternating layers of initially either cold-rolled (CR) or recrystallized (AR) material. After compression bonding followed by cold compression, the microstructure of the initial CR layers is characterized by a fine boundary spacing, while the boundary spacing in the initial AR layers is greater. Annealing of this compression-bonded sample is carried out at $600{ }^{\circ} \mathrm{C}$ to achieve a highly heterogeneous microstructure. During the early stages of annealing, coarsening is more pronounced in the $\mathrm{CR}$ layers leading to a more rapid reduction in the stored energy than in the $\mathrm{AR}$ layers. Further annealing results in recrystallization taking place preferentially in the AR layers with the consequence that the slowly recrystallizing CR layers are considerably harder than the AR layers. Tensile testing demonstrates that in this multilayered microstructure combinations of high strength and comparatively high ductility are achieved in the samples annealed at $600{ }^{\circ} \mathrm{C}$ for either $1 \mathrm{~h}$ or $1.5 \mathrm{~h}$, when the microstructure is strongly heterogeneous with a large difference in the fraction of
\end{abstract}


recrystallized material between the initial CR and AR layers. Such samples with alternating hard and soft layers are found to have a better combination of strength and ductility than other IF-steel samples with a more homogeneous microstructure. The enhanced strength in the annealed multilayered compression-bonded samples can be attributed to the influence of mechanical constraints between the layers.

\section{Keywords:}

Electron microscopy; Hardness; Stress/strain measurements; Iron alloys; Layered structure; Compression bonding

* Corresponding author, ** Corresponding author.

E-mail addresses: zhangling2014@cqu.edu.cn (L.Zhang), olmi@mek.dtu.dk (O.V. Mishin)

\section{Introduction}

A combination of high strength and high ductility is desirable for many structural applications of metals and alloys. It is known that very high strengths can be reached by severe plastic deformation. However, such heavily deformed materials are usually characterized by low ductility. Whereas the ductility can be improved by annealing, this restoration of ductility is typically accompanied by a reduction in strength. This effect, known as the strength-ductility trade-off [1-3], makes achieving good combinations of high strength and high ductility rather challenging. A promising approach to solve this issue is to combine hard and soft regions in bimodal, gradient or microstructurally continuous sandwich structures [3-9], which have been shown to enable a reasonable balance between strength and ductility. Multilayered structures of similar and dissimilar metallic materials can also be obtained, for example, by accumulative roll bonding (ARB). However, when samples containing hard and soft layers are processed by ARB, fragmentation of the hard layers frequently occurs after several ARB 
cycles [10-12]. An alternative technique is to bond layers with different initial microstructures by compression, after which soft and hard layers can be obtained by tailored thermomechanical treatments.

This compression bonding technique has recently been applied to an interstitial-free (IF) steel sample consisting of several cold-rolled and annealed layers [13]. A combination of high strength and reasonably good ductility was obtained in this multilayered sample after annealing in the temperature range, $575^{\circ} \mathrm{C}$ to $625^{\circ} \mathrm{C}$ [13]. During annealing the material demonstrated unexpected behavior, with recrystallization progressing slower in layers that experienced a higher strain before the final annealing treatment. This atypical behavior was not rationalized in the previous communication [13]. Obviously, detailed quantitative analysis is required to understand the evolution of the microstructure during annealing of this multilayered IF steel sample, resulting in the observed combinations of high strength and high ductility. Such an analysis is especially important because compared to IF steel deformed by ARB and other deformation techniques [14-22], the evolution of microstructure and mechanical properties during compression and subsequent annealing of IF steel samples has been studied less extensively.

The present work has two goals: (i) to characterize the as-deformed microstructure of the compressed multilayered IF steel and its evolution during recovery and recrystallization; and (ii) to evaluate the origin of the high strength and good ductility after annealing of this material, based on a quantitative characterization of the microstructure. To accomplish these goals, the microstructure, texture and mechanical behavior of the multilayered IF steel sample are studied in detail in the deformed conditions and after annealing at $600^{\circ} \mathrm{C}$ for different periods of time covering both recovered and recrystallized microstructures. The mechanical properties of the compression bonded IF steel are compared with the properties of IF steels processed using other deformation techniques. 


\section{Experimental}

A $4.5 \mathrm{~mm}$ thick sheet of IF steel containing Fe-0.0012 C-0.005 Si-0.1 Mn-0.061 Ti (wt.\%) was cold-rolled $\sim 78 \%$ to $1 \mathrm{~mm}$ thickness (termed $\mathrm{CR}$ in this work). A part of this material was then annealed at $780^{\circ} \mathrm{C}$ for 45 min to produce a recrystallized (AR) condition. Disks with a diameter of $15 \mathrm{~mm}$ were machined from the $\mathrm{CR}$ and AR conditions. The surface of the disks was ground using sandpaper and cleaned with acetone, after which the discs were stacked to form several cylinders with alternating CR and AR layers (see Fig.1). The height of each cylinder was $11 \mathrm{~mm}$. Care was taken to align each disc with the initial rolling direction (RD) being parallel for all the discs in the cylinders.

The cylinders were then compressed $40 \%$ at $500{ }^{\circ} \mathrm{C}$ in vacuum to create bonding between the layers. The compression axis was parallel to the ND of the rolled sheet (Fig.1), and the thickness of the hot-deformed samples was $6.6 \mathrm{~mm}$. After cooling, the samples were further compressed at room temperature to $1.6 \mathrm{~mm}$ (76\% reduction) using a hydraulic press. In the following, this final compressed condition is referred to as the multilayered compression bonded (MCB) sample. The total von Mises strain achieved for the $\mathrm{CR}$ and $\mathrm{AR}$ layers was $\sim 3.7$ and 1.9, respectively. The MCB sample was subsequently annealed at $600{ }^{\circ} \mathrm{C}$ for different periods of time.

In each sample, microstructural investigations were conducted near the mid-thickness over an area corresponding to several initial layers, always inspecting the plane which contained the RD and ND of the cold-rolled material. The samples were polished mechanically using sandpaper and then electrochemically at $15 \mathrm{~V}$ in a solution containing $10 \%$ perchloric acid in ethanol at a temperature of $-15^{\circ} \mathrm{C}$. Backscattered electron (BSE) images and EBSD data were utilized for quantitative analysis of the microstructure. Step sizes of $25 \mathrm{~nm}$ to $100 \mathrm{~nm}$ were used for EBSD analysis of the heavily deformed and recovered microstructure, while larger step sizes were used for characterizing 
recrystallized grains and texture. The collected EBSD data were processed using the Channel 5 software (HKL Technology) and programs developed in-house [23].

Fractions of different texture components were calculated within $15^{\circ}$ from chosen ideal orientations. Low angle boundaries (LABs) and high angle boundaries (HABs) in the EBSD maps were defined as those with misorientations $\theta=1.5-15^{\circ}$ and $\theta>15^{\circ}$, respectively. The stored energy of boundaries per unit volume was calculated from the EBSD data using the method described by Godfrey et al. [24]. The specific boundary energy of LABs was calculated from the Read-Shockley equation $[25,26]$. The specific boundary energy of HABs was taken as $0.617 \mathrm{~J} / \mathrm{m}^{2}$ [27]. Recrystallized grains were identified based on the method described in Ref. [23]. In the present work, such grains were defined as regions greater than $3 \mu \mathrm{m}$ with internal misorientations of less than $1^{\circ}$ surrounded by boundaries with $\theta \geq 2^{\circ}$. An additional criterion was that each recrystallized grain should be at least partially surrounded by HABs.

Dogbone shaped specimens with a gauge length of $12 \mathrm{~mm}$ and a width of $2.5 \mathrm{~mm}$ were used for tensile testing along the original RD. The testing was carried out at a constant crosshead speed of $0.5 \mathrm{~mm} / \mathrm{min}$, corresponding to an initial strain rate of $8.3 \times 10^{-4} \mathrm{~s}^{-1}$. Two specimens were tensile tested for each condition. Vickers hardness was measured in the initial CR and AR samples using a load of $200 \mathrm{~g}$ and $10 \mathrm{~s}$ dwell time. Vickers hardness measurements were also made in the central zone of the annealed multilayered samples, which were sectioned along the compression axis. In this case, a load of either $25 \mathrm{~g}$ or $10 \mathrm{~g}$ was used to measure the hardness of individual $\mathrm{CR}$ and AR layers, where each average value typically represented ten indentations in the middle of the layers. 


\section{Results}

\subsection{Initial stack and MCB sample}

The microstructure in the different layers forming the initial stack before compression bonding is shown in Fig.2. As expected, grains in the cold-rolled material are elongated along the RD (Fig.2(a)), and are further subdivided by deformation-induced boundaries with mostly low angle misorientations and occasionally high angle misorientations. The average boundary spacing $d$ in this CR layer is $0.4 \mu \mathrm{m}$. The average grain size in the recrystallized AR layer (Fig.2(b)) measured using the line intercept method is $\sim 15 \mu \mathrm{m}$. The hardness values of the CR and AR layers are $187 \mathrm{HV}$ and $77 \mathrm{HV}$, respectively. The initial stack sample contains a pronounced $\gamma$-fiber $\langle 111\rangle / / \mathrm{ND}$ in each layer, with a greater intensity of this fiber in the AR layers (see Fig.3(a,b)). Additionally, a partial $\alpha$-fiber $\langle 110\rangle / / \mathrm{RD}$ and a $\{100\}\langle 011\rangle$ ND-rotated cube $\left(\mathrm{Cube}_{\mathrm{ND}}\right)$ component are seen in the texture of the CR layers (Fig.3(a)).

In the MCB sample, the texture is different: the $\alpha$-fiber is no longer observed in the CR layers, whereas the intensity of the $\langle 111\rangle / / \mathrm{ND}$ fiber increases (cf. Fig.3(a) and Fig.3(c)). The Cube $\mathrm{ND}$ component becomes strong with a considerable spread of orientations (see Fig.3(c)). Both the Cube ND component and the spread belong to the $\langle 100\rangle / / \mathrm{ND}$ fiber. Area fractions of the $\langle 111\rangle / / \mathrm{ND}$ and $\langle 100\rangle / / \mathrm{ND}$ fibers (in the following, $\langle 111\rangle$ and $\langle 100\rangle$ fibers) in the CR layers of the MCB sample are $f_{\langle 111\rangle}=43 \%$ and $f_{\langle 100\rangle}=56 \%$ (Table 1). In the AR layers (Fig.3(d)), the difference in the area fractions of these fibers is greater: the $\langle 111\rangle$ fiber occupies $86 \%$ of the area, whereas the $\langle 100\rangle$ fiber is weak $(12 \%)$. Deformation structures containing extended dislocation boundaries are observed in each layer of the MCB sample (Fig.4 and Fig.5(a,b)). In the as-deformed condition, the subgrain size $d_{\mathrm{S}}$ measured along random lines is found to be $216 \mathrm{~nm}$ in the CR layers and $323 \mathrm{~nm}$ in the AR layers (Fig.6(a)). These 
values are significantly larger than the boundary spacing only along the ND reported in Ref.[13]. The aspect ratios of the subgrains are slightly above 4 and 3 in the $C R$ and AR layers, respectively (see Fig.6(b)). The fraction of HABs $\left(f_{\mathrm{HAB}}\right)$ is $52 \%$ in the CR layers and $17 \%$ in the AR layers (Table 1$)$. Differences in the microstructural evolution between these layers during annealing are presented in the following section.

Table 1. Parameters of the microstructure and texture measured using EBSD in the CR and AR layers of the MCB sample.

\begin{tabular}{lllcc}
\hline Layer & $d_{\mathrm{S}}(\mathrm{nm})$ & $f_{\mathrm{HAB}}(\%)$ & $f_{\langle 111\rangle}(\%)$ & $f_{\langle 100\rangle}(\%)$ \\
\hline $\mathrm{CR}$ & 216 & 52 & 43 & 56 \\
$\mathrm{AR}$ & 323 & 17 & 86 & 12 \\
\hline
\end{tabular}

\subsection{Effects of annealing on microstructural heterogeneity}

After only $10 \mathrm{~min}$ at $600{ }^{\circ} \mathrm{C}$ the microstructure obtained in the MCB sample coarsens to $660 \mathrm{~nm}$ in the CR layers and to $570 \mathrm{~nm}$ in the AR layers (see Fig.5(c,d) and Fig.6(a)). The coarsening is accompanied by bulging of extended boundaries and the subgrain aspect ratio decreases to almost 2 (Fig.6(b)). Between $10 \mathrm{~min}$ and $0.5 \mathrm{~h}$ the coarsening accompanied by bulging continues (Fig.7(a,b)) and recrystallization begins. Comparing the different layers, recrystallized grains are more frequent in the AR layers, where they are predominantly located near the initial layer interfaces. Most of these grains have $\langle 111\rangle$ orientations (blue in Fig.8). These grains are also larger than other recrystallized grains (Fig.9(b)). The area fractions of the recrystallized microstructure $\left(f_{\text {Rex }}\right)$ after $0.5 \mathrm{~h}$ of annealing are $1 \%$ and $8 \%$ in the CR and AR layers, respectively (see Fig.9(a)). 
During further annealing the structures in the non-recrystallized volumes continue to coarsen faster in the CR layers, while recrystallization progresses more rapidly in the AR layers (Fig.7(c,d), Fig.8 and Fig.9(a)). After $1 \mathrm{~h}$ of annealing $f_{\text {Rex }}$ is $43 \%$ in the AR layers and only $7 \%$ in the CR layers (see Fig.8(b) and Appendix A). In the sample annealed for $1.5 \mathrm{~h}, f_{\mathrm{Rex}}$ is $72 \%$ and $18 \%$ in the $\mathrm{AR}$ and $\mathrm{CR}$ layers, respectively. In each layer, the average size of recrystallized $\langle 111\rangle$ grains is larger than that of the $\langle 100\rangle$ grains (Fig.9(b)). After annealing for $4 \mathrm{~h}$, the AR layer is almost fully recrystallized $\left(f_{\mathrm{Rex}}=96 \%\right)$, whereas the CR layers are only 50\% recrystallized (Fig.8(d) and Fig.9(a)). The average recrystallized grain size $D_{\mathrm{Rex}}$ in this condition is approximately $6 \mu \mathrm{m}$ and $10 \mu \mathrm{m}$ in the CR and AR layers, respectively.

\subsection{Mechanical behavior of the multilayered samples}

The evolution of Vickers hardness during annealing at $600{ }^{\circ} \mathrm{C}$ is shown in Fig.10(a). This figure demonstrates a significant drop in hardness after 10 min of annealing, leading to a reduction in the difference in $\mathrm{HV}$ between the layers. Further annealing at $600{ }^{\circ} \mathrm{C}$ causes almost linear softening in the CR layers between $0.5 \mathrm{~h}$ and $4 \mathrm{~h}$. The AR layers soften much more rapidly than the CR layers between $0.5 \mathrm{~h}$ and $2 \mathrm{~h}$, followed by slower softening between $2 \mathrm{~h}$ and $4 \mathrm{~h}$. The largest relative difference in hardness (above 30\%) between the AR and CR layers is achieved for the samples annealed for $1.5 \mathrm{~h}$ to $3 \mathrm{~h}$.

The cold-deformed MCB sample and the partially recrystallized samples annealed at $600{ }^{\circ} \mathrm{C}$ for $1 \mathrm{~h}$ and $1.5 \mathrm{~h}$ were chosen for tensile testing. Stress-strain curves for these samples are presented in Fig.10(b). In addition, the stress-strain curve for the initial AR sheet is included to show the mechanical behavior of the fully recrystallized material. It is evident that each sample demonstrates continuous flow with no yield drop. 
The MCB sample is characterized by a high $0.2 \%$ proof stress $\left(\sigma_{0.2}=738 \mathrm{MPa}\right)$, an ultimate tensile strength (UTS) of $763 \mathrm{MPa}$ and a low uniform elongation $e_{\mathrm{u}}$ of approximately $1 \%$, see Table 2 . The uniform elongation increases to $14 \%$ after annealing for $1 \mathrm{~h}$, while $\sigma_{0.2}$ and UTS decrease to $473 \mathrm{MPa}$ and $604 \mathrm{MPa}$, respectively. After annealing for $1.5 \mathrm{~h}, \sigma_{0.2}$ is $417 \mathrm{MPa}$, the UTS is $536 \mathrm{MPa}$ and $e_{\mathrm{u}}$ is $19 \%$. These combinations of fairly high strength and high uniform elongation in the partially recrystallized multilayered IF steel sample are remarkable and have not been reported for IF steel processed using other deformation techniques such as rolling, ARB or equal channel angular extrusion (ECAE), where in each case a more uniform microstructure is developed upon annealing.

Table 2. Tensile test data and Vickers hardness of the MCB sample in the as-deformed condition and after annealing at $600{ }^{\circ} \mathrm{C}$. Vickers hardness is presented separately for the $\mathrm{CR}$ and $\mathrm{AR}$ layers.

\begin{tabular}{llllll}
\hline Sample & $\sigma_{0.2}(\mathrm{MPa})$ & $\mathrm{UTS}(\mathrm{MPa})$ & $e_{\mathrm{u}}(\%)$ & $\mathrm{HV}_{\mathrm{CR}}$ & $\mathrm{HV}_{\mathrm{AR}}$ \\
\hline MCB & $738 \pm 45$ & $763 \pm 21$ & $0.9 \pm 0.3$ & $220 \pm 4$ & $193 \pm 6$ \\
MCB $600{ }^{\circ} \mathrm{C} 1 \mathrm{~h}$ & $473 \pm 6$ & $604 \pm 2$ & $14^{*}$ & $124 \pm 3$ & $110 \pm 6$ \\
MCB $600{ }^{\circ} \mathrm{C} 1.5 \mathrm{~h}$ & $417 \pm 8$ & $536 \pm 3$ & $19^{*}$ & $123 \pm 6$ & $92 \pm 5$ \\
\hline
\end{tabular}

*The standard deviation is less than 0.1

\section{Discussion}

In the following, we consider the microstructural evolution of the multilayered IF-steel sample first during the step combining compression bonding at $500{ }^{\circ} \mathrm{C}$ and room temperature compression, and then during subsequent annealing, followed by a discussion of the mechanical behavior of this multilayered sample as compared to IF steel samples processed using other techniques. 


\subsection{Effects of compression on microstructure and texture}

The microstructure and texture of the $78 \%$ rolled sheet (CR layers) is typical of body centered cubic (bcc) steels deformed to a similar strain, with the boundary spacing in the submicron range and two pronounced $\gamma\langle 111\rangle / / \mathrm{ND}$ and $\alpha\langle 110\rangle / / \mathrm{RD}$ fibers $[17,18]$, where the intensity of the Cube $\mathrm{ND}$ component is also significant (see Fig.3(a)). In the AR condition the material is fully recrystallized and contains a stronger $\gamma$ fiber than that in the CR material. Thus, the initial sample before compression represents a stack of alternating hard and soft layers with very different microstructures and significant differences in texture.

During compression the texture changes, as crystal orientations rotate towards the stable components of the compression texture. Such stable components in bcc materials are known to be fibers with $\langle 111\rangle$ and $\langle 100\rangle$ parallel to the compression axis [28-31]. It should be noted that for the present sample, which was compressed along the ND of the rolled material, the $\gamma$ fiber of the rolling texture is coincident with the $\langle 111\rangle$ fiber of the compression texture. Therefore, differences in the intensity of the $\gamma$ fiber in the initial texture can be inherited in the compression texture. The $\gamma$ fiber was initially stronger in the AR sample than in the CR sample (see Fig.3(a,b)). It is therefore not surprising that in the MCB sample the $\langle 111\rangle$ fiber is also significantly stronger in the AR layers than in the CR layers. In contrast to the $\gamma$ fiber, the $\alpha$ fiber initially present in the CR sample (Fig.3(a)) is no longer seen after compression (Fig.3(c)). One exception is the Cube $\mathrm{ND}_{\mathrm{ND}}$ component, which belongs both to the $\alpha$ fiber of the rolling texture and to the $\langle 100\rangle$ fiber of the compression texture, and this component is retained in the $\mathrm{CR}$ layers of the $\mathrm{MCB}$ sample. Compared to the initial texture, the $\langle 100\rangle$ fiber strengthens in intensity and spreads along the compression axis, forming an incomplete $\langle 100\rangle$ fiber in 
the CR layers in the MCB sample (Fig.3(c)). A weak $\langle 100\rangle$ fiber is also formed in the AR layers (see Fig.3(d)).

As expected, the deformed microstructure in the CR layers is further refined during compression resulting in a very fine boundary spacing, while the boundary spacing in the initially recrystallized AR layers is greater (see Table 1). Another significant difference is that the fraction of HABs in the CR layers is much larger than that in the AR layers (Table 1). The influence of these differences on the microstructural evolution during annealing is discussed in the next section.

\subsection{Microstructural coarsening during annealing}

One result that appears paradoxical is that the CR layers in the MCB sample, which experience a higher total strain and contain more finely spaced deformation-induced boundaries, recrystallize slower than the AR layers. To rationalize this interesting result, we first analyze the evolution of the microstructure during recovery prior to recrystallization, i.e. within the first 10 min at $600{ }^{\circ} \mathrm{C}$ when the deformed microstructure only coarsens. Such coarsening of the deformed microstructure during recovery is likely to involve lateral migration of triple junctions [32,33], leading to significant changes in the subgrain size and aspect ratio (see Fig.6). The coarsening is more pronounced in the CR layers, which drastically changes the relative difference in the average subgrain size in the different layers. Although $d_{\mathrm{S}}$ in the CR layers was smaller than that in the AR layers before annealing, already after 10 min at $600{ }^{\circ} \mathrm{C}$ the microstructure becomes coarser in the $\mathrm{CR}$ layers than in the $\mathrm{AR}$ layers (see Fig.6(a)). The significant difference in the extent of coarsening between the CR and AR layers can be explained by the different availability of HABs in these layers. Since the fraction of HABs in the CR layers is much higher than $f_{\mathrm{HAB}}$ in the AR layers (see Table 1), there are many more mobile boundaries to promote greater coarsening in the $\mathrm{CR}$ layers. 
Considering that the microstructure in the AR and CR layers of the MCB sample is split into $\langle 111\rangle$ and $\langle 100\rangle$ texture bands, it is useful to analyze the stored energy within regions of the different texture components. The stored energy per unit volume due to boundaries within the different regions can be evaluated based on the EBSD data [24]. The result of the analysis for non-recrystallized regions is shown in Fig.11. It is seen that after compression the $\langle 111\rangle$ regions in each layer have a higher stored energy than the $\langle 100\rangle$ regions, which is due to the fact that the Taylor factor in bcc materials for grains compressed along the $\langle 111\rangle$ direction is higher than that along the $\langle 100\rangle$ direction. Qualitatively similar results have been reported for other compressed steel samples [29,30]. Additionally, it is evident that for the as-deformed MCB sample the stored energy in regions of both the $\langle 111\rangle$ and $\langle 100\rangle$ fibers is higher in the CR layers than in the AR layers. The highest stored energy is calculated to be in the $\langle 111\rangle$ regions of the CR layers (see Fig.11).

As a result of coarsening, the stored energy decreases in regions of each texture component. However, within the first $10 \mathrm{~min}$ of annealing this reduction is greatest in the $\langle 111\rangle$ regions of the CR layers, so that after annealing they are no longer the regions with the highest stored energy. As is seen in Fig.11, the highest stored energy in the recovered microstructure is in the $\langle 111\rangle$ regions of the AR layers. Therefore, there is a higher remaining driving force for recrystallization in these regions.

\subsection{Recrystallization}

In the present material recrystallization starts between $10 \mathrm{~min}$ and $0.5 \mathrm{~h}$ of annealing at $600{ }^{\circ} \mathrm{C}$, i.e. when the as-deformed microstructure is already significantly modified by coarsening. As follows from the analysis of the stored energy presented in section 4.2, recrystallization in this coarsened microstructure is expected to proceed faster in the $\langle 111\rangle$ regions of the AR layers with the highest remaining stored energy (Fig.11). Indeed, the AR layers are observed to recrystallize more rapidly than 
the CR layers (see Fig.8 and Fig.9(a)). The fact that in the beginning of recrystallization $(0.5 \mathrm{~h}$ at $600{ }^{\circ} \mathrm{C}$ ) more grains nucleate near interfaces to the $\mathrm{CR}$ layers implies that the microstructure in these near-interface regions is somewhat different from that in the core of the AR layers. However, after annealing for $1.5 \mathrm{~h}$ and above, recrystallized grains occupy the majority of the AR layers, while $f_{\text {Rex }}$ in the CR layers is still between $20 \%$ and $50 \%$.

Since for the CR layers the stored energy is higher in the $\langle 111\rangle$ regions than in the $\langle 100\rangle$ regions (Fig.11), recrystallized grains in these layers nucleate preferentially also in the $\langle 111\rangle$ regions and therefore mostly have orientations of the $\langle 111\rangle$ fiber (see Fig.8(c,d)). Therefore, recrystallization in the compressed IF steel is strongly orientation-dependent. In contrast to several previous studies of compressed steels, where the deformation texture was significantly altered during orientationdependent recrystallization [29-31], recrystallization in the MCB sample did not result in considerable texture changes. This is attributed to the specific distribution of texture components in the different layers of the MCB sample, where the favorable $\langle 111\rangle$ component of the recrystallization texture was the dominant fiber in the AR layers before annealing, while recrystallization in the CR layers remained far from being complete and hence a pronounced $\langle 100\rangle$ component was retained here.

It is of interest to consider misorientations between recrystallized grains of the different texture components and their recovered environment. In the present work, this is done for the sample annealed for $0.5 \mathrm{~h}$, i.e. at an early stage of recrystallization. Comparing such misorientations for grains in the CR layers (Fig.12(a,b)), it is evident that boundaries of the $\langle 111\rangle$ grains are characterized by a greater fraction of high angle misorientations and greater fractions of both $\langle 111\rangle$ and $\langle 110\rangle$ misorientation axes. The higher fraction of mobile HABs for recrystallized $\mathrm{CR}\langle 111\rangle$ grains can be an additional reason for their faster propagation during extended annealing as compared to the CR $\langle 100\rangle$ grains (see Fig.9(b)). 
However, taking into account that in the AR layers, the $\langle 111\rangle$ grains grow faster than the $\langle 100\rangle$ grains despite a slightly lower fraction of HABs with the matrix (67\% in Fig.12(c) vs 70\% in Fig.12(d)), the proportion of HABs and LABs seems less important for the average recrystallized grain size than the difference in the stored energy between the recovered $\langle 111\rangle$ and $\langle 100\rangle$ regions.

\subsection{Mechanical properties of multilayered IF-steel}

It is important to emphasize that the multilayered samples were prepared in the present experiment with the objective of having a strongly heterogeneous microstructure. In this material the finer lamellar structure formed due to the higher total strain in the CR layers of the MCB sample results in higher hardness than that in the AR layers (Fig.10(a) and Table 2). During annealing the material softens significantly, with the pronounced drop in hardness observed after the first $10 \mathrm{~min}$ at $600{ }^{\circ} \mathrm{C}$, i.e. when the deformed microstructure has only coarsened with no apparent sign of recrystallization. In this recovered microstructure the difference in hardness between the layers is small. Since recrystallization progresses faster in the AR layers, the relative difference in hardness between these layers increases during partial recrystallization, so that after extended annealing the AR layers are considerably softer than the CR layers (see Fig.10(a) and Table 2). It has previously been suggested that the presence of alternating soft and hard layers result in a deformation constraint leading to enhanced strengthening $[34,35]$. To evaluate possible constraint-induced effects for the present material, Vickers hardness measured in individual layers and $\sigma_{0.2}$ determined by tensile tests are plotted in Fig.13(a) as a function of $1 / \sqrt{d}$, where $d$ is the average boundary spacing.

For individual layers $d$ was defined as

$$
d=d_{\mathrm{S}}\left(1-f_{\mathrm{Rex}}\right)+D_{\mathrm{Rex}} f_{\mathrm{Rex}}
$$

where $d_{\mathrm{S}}$ is the average subgrain size in the deformed and recovered microstructure of either the CR or 
AR layers, while $D_{\text {Rex }}$ and $f_{\text {Rex }}$ are, respectively, the average size and area fraction of recrystallized grains in the different layers.

For the tensile test specimens, which consisted of six CR layers and five AR layers, $d$ was calculated as an average of the boundary spacings in the CR and AR layers:

$$
d=\left(6 d_{\mathrm{CR}}+5 d_{\mathrm{AR}}\right) / 11
$$

In addition to the data for the multilayered samples, Fig.13(a) also presents $\mathrm{HV}$ and $\sigma_{0.2}$ data obtained for the initial CR and AR sheets. The dashed line in this figure is drawn between the HV data points for the initial (unconstrained) CR and AR sheets. It is obvious that most of the hardness data for the multilayered samples fall sufficiently close to this line, indicating no constraint effect for these measurements. This is reasonable since hardness in these samples was measured using small loads in the middle of individual layers. The yield strengths of the initial CR and AR sheets as well as the yield strength of the MCB sample also fall close to this line, which suggests that there were no significant constraints between the layers in the latter sample containing only the deformed microstructure. However, for the annealed multilayered samples with a highly heterogeneous microstructure and large differences in $f_{\text {Rex }}$ between the layers, the yield strength is significantly higher than that expected based on the HV data, thus indicating a possible constraint effect.

Furthermore, the mechanical strength of the samples studied in the present work is compared in Fig.13(b) with that of several IF steel samples annealed after ARB, which had a far less heterogeneous microstructure in the bonded layers $[14,15]$ and which demonstrated continuous flow (no yield drop) during tensile testing. It is significant that yield strengths of the AR sample and a recrystallized ARB sample with a similar grain size (two data points at the lower left corner of Fig.13(b)) are very similar. This suggests that differences in the chemical composition and texture of the steels used in the present 
experiment and in $[14,15]$ do not significantly affect the measured strength. Comparing the data points for the annealed ARB and MCB samples, the yield strength of the latter samples is substantially higher (see Fig.13(b)). Taking into account that the major difference between these two types of samples is the extent of microstructural heterogeneity (hence different hardness variations), it can be proposed that mechanical constraints between the hard and softer layers of the annealed MCB samples play a significant role in enhancing their strength.

To complement the mechanical data previously presented in Ref.[13], Fig.14 shows the uniform elongation plotted versus UTS and compares the data obtained for the present material with a large number of literature data for the IF steels [14-16,19-22]. It is evident that for several annealed MCB samples combinations of UTS and ductility are superior compared to those reported in the literature. This can indicate a general advantage of the heterogeneous multilayered structure, where hard regions and mechanical constraints between the layers enhance the strength, while soft regions enable comparatively high ductility. Manufacturing multilayered samples with appreciate differences in the extent of recrystallization in different layers appears therefore to be an efficient approach to enhance both strength and ductility, which can be used as a guideline for future microstructure design and optimization of mechanical properties of single phase materials.

\section{Conclusions}

An investigation of the microstructure and mechanical properties in an IF-steel sample consisting of alternating layers of either cold-rolled (CR) or annealed/recrystallized (AR) material bonded by hot compression and subsequently cold-compressed and annealed at $600{ }^{\circ} \mathrm{C}$ has revealed the following:

1) Since the total accumulated strain in the CR layers of the MCB sample is much higher than that in the AR layers, the deformed microstructure in the CR layers is finer and has a higher stored energy 
than that in the AR layers. Crystallographic textures are also different in these layers: the area fractions of the $\langle 111\rangle$ and $\langle 100\rangle$ fibers in the CR layers are $43 \%$ and $56 \%$, respectively, whereas in the AR layers the $\langle 111\rangle$ fiber and the $\langle 100\rangle$ fiber occupy $86 \%$ and $12 \%$, respectively. Comparing regions of the different texture components in the different layers, the $\langle 111\rangle$ regions in the CR layers are found to have the highest stored energy.

2) Within the first $10 \mathrm{~min}$ of annealing at $600{ }^{\circ} \mathrm{C}$ the microstructure in each layer coarsens with no apparent sign of recrystallization. The coarsening is more pronounced in the CR layers, where the mean subgrain size increases from $216 \mathrm{~nm}$ to $660 \mathrm{~nm}$ in the CR layers, while it increases from $323 \mathrm{~nm}$ to $570 \mathrm{~nm}$ in the AR layers. The reduction of the stored energy due to coarsening is greatest in the $\langle 111\rangle$ regions of the CR layers, so that after annealing they are no longer regions with the highest stored energy. The highest stored energy in the recovered microstructure is found to be in the $\langle 111\rangle$ regions of the AR layers, which provides a higher driving force for recrystallization than that in the other regions.

3) Recrystallization begins during annealing beyond $10 \mathrm{~min}$ at $600{ }^{\circ} \mathrm{C}$ and progresses faster in the $\mathrm{AR}$ layers than in the CR layers. Recrystallization takes place predominantly in the $\langle 111\rangle$ regions, with the largest average recrystallized grain size observed in the AR layer. After annealing for $1.5 \mathrm{~h}$ and above, recrystallized grains occupy the majority of the AR layers, while the fraction of recrystallized grains in the CR layers is only $50 \%$ even after $4 \mathrm{~h}$ of annealing. The slower recrystallization in the $\mathrm{CR}$ layers is a direct consequence of the greater coarsening during recovery. The CR layers containing substantially lower fractions of recrystallized material are considerably harder than the AR layers. 
4) Tensile testing reveals combinations of high strength and comparatively high ductility in the MCB samples annealed at $600{ }^{\circ} \mathrm{C}$ for either $1 \mathrm{~h}$ or $1.5 \mathrm{~h}$, i.e. when the microstructure is strongly heterogeneous with a large difference in the fraction of recrystallized material between the initial CR and AR layers. Such annealed samples with alternating hard and soft layers are found to have a better combination of strength and ductility than other IF-steel samples with a more homogeneous microstructure. The enhanced strength in these annealed multilayered compression bonded samples can be attributed to the influence of mechanical constraints between the layers.

Acknowledgments The authors wish to thank the financial supports of the State Key Research and Development Program of MOST, China (Grant No. 2016YFB0700400) and the National Natural Science Foundation of China (NSFC, Grant Nos. 51671039 and 51421001). XJ and OVM thank the support of the 111 Project (B16007) by the Ministry of Education and the State Administration of Foreign Experts Affairs, China. Useful discussions with Professor A. Godfrey are gratefully acknowledged.

\section{Appendix A. Supplementary data}

Supplementary data to this article can be found online at [insert the link]

\section{References}

[1] C.W. Shao, P. Zhang, Y.K. Zhu, Z.J. Zhang, Y.Z. Tian, Z.F. Zhang, Simultaneous improvement of strength and plasticity: Additional work-hardening from gradient microstructure, Acta Mater. 145 (2018) 413-428. 
[2] Y. Wei, Y. Li, L. Zhu, Y. Liu, X. Lei, G. Wang, Y. Wu, Z. Mi, J. Liu, H. Wang, H. Gao, Evading the strength-ductility trade-off dilemma in steel through gradient hierarchical nanotwins, Nat. Commun. 5 (2014) 3580.

[3] Y. Wang, M. Chen, F. Zhou, E. Ma, High tensile ductility in a nanostructured metal, Nature 419 (2002) 912-915.

[4] Y. Zhao, T. Topping, Y.Li, E.J. Lavernia, Strength and ductility of bi-modal Cu, Adv. Eng. Mater. 13 (2011) 865-871.

[5] T.H. Fang, W.L. Li, N.R. Tao, K. Lu, Revealing extraordinary intrinsic tensile plasticity in gradient nano-grained copper, Science 331 (2011) 1587-1590.

[6] K. Lu, Making strong nanomaterials ductile with gradients, Science 345 (2014) 1455-1456.

[7] X.L. Wu, M.X. Yang F.P. Yuan, G.L. Wu, Y.J. Wei, X. Huang, Y.T. Zhu, Heterogeneous lamella structure unites ultrafine-grain strength with coarse-grain ductility, PNAS 112 (2015) 14501-14505.

[8] J.-L. Zhang, C.C. Tasan, M.J. Lai, D. Yan, D. Raabe, Partial recrystallization of gum metal to achieve enhanced strength and ductility, Acta Mater. 135 (2017) 400-410.

[9] A. Godfrey, O.V. Mishin, Controlled annealing of sandwich-structured aluminum AA1050 for optimized combinations of strength and ductility, Mater. Sci. Eng. A735 (2018) 228-235.

[10] A. Mozaffari, H. Danesh Manesh, K. Janghorban, Evaluation of mechanical properties and structure of multilayered $\mathrm{Al} / \mathrm{Ni}$ composites produced by accumulative roll bonding (ARB) process, $J$. Alloys Compnd. 489 (2010) 103-109.

[11] K. Wu, H. Chang, E. Maawad, W.M. Gan, H.G. Brokmeier, M.Y. Zheng, Microstructure and mechanical properties of the $\mathrm{Mg} / \mathrm{Al}$ laminated composite fabricated by accumulative roll bonding (ARB) Mater. Sci. Eng. A 527 (2010) 3073-3078. 
[12] M. Hosseini, N. Pardis, H.D. Manesh, M. Abbasi, D.-I. Kim, Structural characteristics of Cu/Ti bimetal composite produced by accumulative roll-bonding (ARB), Mater. Des. 113 (2017) 128-136. [13] L. Zhang, Z. Chen, Y. Wang, G. Ma, T. Huang, G. Wu, D. Juul Jensen, Fabricating interstitial-free steel with simultaneous high strength and good ductility with homogeneous layer and lamella structure, Scr. Mater. 141 (2017) 111-114.

[14] S. Gao, M. Chen, M. Joshi, A. Shibata, N. Tsuji, Yielding behavior and its effect on uniform elongation in IF steel with various grain sizes, J. Mater. Sci. 49 (2014) 6536-6542.

[15] S. Gao, M. Chen, S. Chen, N. Kamikawa, A. Shibata, N. Tsuji, Yielding behavior and its effect on uniform elongation of fine grained IF steel, Mater. Trans. 55 (2014) 73-77.

[16] N. Tsuji, Y. Ito, Y. Saito, Y. Minamino, Strength and ductility of ultrafine grained aluminum and iron produced by ARB and annealing, Scr. Mater. 47 (2002) 893-899.

[17] D. Vanderschueren, N. Yoshinaga, K. Koyama, Recrystallisation of Ti IF steel investigated with electron back scattering pattern (EBSP), ISIJ Int. 36 (1996) 1046-1054.

[18] I. Samajdar, B. Verlinden, P. Van Houtte, D. Vanderschueren, $\gamma$-fibre recrystallization texture in IF-steel: an investigation on the recrystallization mechanisms, Mater. Sci. Eng. A A238 (1997) 343350.

[19] A.P. da Rocha Santos, T.C. da Mota, H.V.G. Segundo, L.H. de Almeida, L.S. Araújo, A. da Cunha Rocha, Texture, microstructure and anisotropic properties of IF-steels with different additions of titanium, niobium and phosphorus, J. Mater. Res. Technol. 7 (2018) 331-336.

[20] B.L. Li, A. Godfrey, Q.C. Meng, Q. Liu, N. Hansen, Microstructural evolution of IF-steel during rolling, Acta Mater. 52 (2004) 1069-1081. 
[21] G. Purcek, O. Saray, I. Karaman, H.J. Maier, High strength and high ductility of ultrafine-grained interstitial-free steel produced by ECAE and annealing, Metall. Mater. Trans. A43 (2012) 4682-4693. [22] S.S. Hazra, E.V. Pereloma, A.A. Gazder, Microstructure and mechanical properties after annealing of equal-channel angular pressed interstitial-free steel, Acta Mater. 59 (2011) 4015-4029.

[23] G.L. Wu, D. Juul Jensen, Automatic determination of recrystallization parameters based on EBSD mapping, Mater. Charact. 59 (2008) 794-800.

[24] A. Godfrey, W.Q. Cao, N. Hansen, Q. Liu, Stored energy, microstructure, and flow stress of deformed metals. Metall. Mater. Trans. A 36 (2005) 2371-2378.

[25] W.T. Read, W. Shockley, Dislocation models of crystal grain boundaries. Phys. Rev. 78 (1950) $275-289$.

[26] W.T. Read, Dislocation in solids. (1953) McGraw-Hill, New York, pp 155-172.

[27] F.J. Humphreys, M. Hatherly, Recrystallization and related annealing phenomena, 2nd ed. (2004) Elsevier Ltd, Oxford.

[28] H. Hu, Texture of metals, Texture 1 (1974) 233-258.

[29] Z.B. Zhang, N.R. Tao, O.V. Mishin, W. Pantleon, Oxide dispersion-strengthened steel PM2000 after dynamic plastic deformation: nanostructure and annealing behavior, J. Mater. Sci. 51 (2016) $5545-5555$.

[30] Z.B. Zhang, Y.B. Zhang, O.V. Mishin, N.R. Tao, W. Pantleon, D. Juul Jensen, Microstructural analysis of orientation-dependent recovery and recrystallization in a modified $9 \mathrm{Cr}-1 \mathrm{Mo}$ steel deformed by compression at a high strain rate, Metall. Mater. Trans. A47 (2016) 4682- 4693.

[31] Z.B. Zhang, O.V. Mishin, N.R. Tao, W. Pantleon, Effect of dynamic plastic deformation on microstructure and annealing behaviour of modified 9Cr-1Mo steel, Mater. Sci. Technol. 31 (2015) $715-721$. 
[32] T. Yu, N. Hansen, X. Huang, Recovery by triple junction motion in aluminium deformed to ultrahigh strains, Proc. Roy. Soc. A 467 (2011) 3039-3065.

[33] O.V. Mishin, A. Godfrey, D. Juul Jensen, N. Hansen, Recovery and recrystallization in commercial purity aluminum cold rolled to an ultrahigh strain, Acta Mater. 61 (2013) 5354-5364.

[34] Y. Du, G. Fan, T. Yu, N. Hansen, L. Geng, X. Huang, Laminated Ti-Al composites: Processing, structure and strength, Mater. Sci. Eng. A673 (2016) 572-580.

[35] Y.H. Wang, J.M. Kang, Y. Peng, T.S. Wang, N. Hansen, X. Huang, Hall-Petch strengthening in Fe-34.5Mn-0.04C steel cold-rolled, partially recrystallized and fully recrystallized, Scr. Mater. 155 (2018) 41-45. 


\section{Figure captions}

Fig.1. A schematic illustration of the initial stack of discs representing CR (light blue) and AR (dark blue) layers, where each disc is aligned with the initial RD.

Fig.2. Orientation maps from the different layers forming the initial stack before compression bonding:

(a) CR layer; (b) AR layer. Different colors in the maps correspond to different crystallographic directions along the ND as shown in the inset in Fig.2(b). White and black lines indicate LABs and HABs, respectively. The RD is parallel to the scale bar.

Fig. 3. ODF sections representing texture in the CR layers $(a, c)$ and $A R$ layers $(b, d)$ of the initial stack before compression bonding (a,b) and in the MCB sample (c,d). Contour layers: 1, 3, 5, 10, 20, 30, 40 $\times$ random.

Fig.4. Orientation maps for the MCB sample: (a) CR layer; (b) AR layer. Different colors correspond to different crystallographic directions along the ND as shown in the inset in Fig.2(b). White and black lines indicate LABs and HABs, respectively.

Fig.5. BSE images showing the effect of short-time annealing at $600{ }^{\circ} \mathrm{C}$ on the microstructure in the $\mathrm{CR}(\mathrm{a}, \mathrm{c})$ and $\mathrm{AR}(\mathrm{b}, \mathrm{d})$ layers of the MCB sample: $(\mathrm{a}, \mathrm{b})$ deformed microstructure; $(\mathrm{c}, \mathrm{d})$ microstructure after annealing for $10 \mathrm{~min}$.

Fig.6. Parameters of the deformed and recovered microstructure in the CR and AR layers of the asdeformed and annealed MCB samples: (a) average subgrain size; (b) average aspect ratio.

Fig.7. Orientation maps representing predominantly recovered regions in the MCB sample annealed at $600{ }^{\circ} \mathrm{C}$ for $0.5 \mathrm{~h}(\mathrm{a}, \mathrm{b})$ and $1 \mathrm{~h}(\mathrm{c}, \mathrm{d})$ : CR layers (a,c); AR layers (b,d). Nucleation of recrystallized grains is clearly observable in $(b, d)$. Different colors correspond to different crystallographic directions along the ND as shown in the inset in Figure 2(b). White and black lines indicate LABs and HABs, 
respectively.

Fig.8. Orientation maps for the MCB sample after annealing at $600{ }^{\circ} \mathrm{C}$ : (a) $0.5 \mathrm{~h}$; (b) $1 \mathrm{~h}$; (c) $2 \mathrm{~h}$; (d) $4 \mathrm{~h}$ showing that AR layers recrystallize much faster than the CR layers. Different colors correspond to different crystallographic directions along the ND as shown in the inset in Fig.2(b). White and black lines indicate LABs and HABs, respectively.

Fig.9. Changes in the area fraction $f_{\text {Rex }}$ (a) and average size $D_{\text {Rex }}$ (b) of recrystallized grains in the CR and AR layers during annealing of the MCB sample at $600{ }^{\circ} \mathrm{C}$. In (b) $D_{\text {Rex }}$ is presented separately for grains of either $\langle 111\rangle$ or $\langle 100\rangle$ texture component.

Fig.10. Mechanical properties: (a) evolution of Vickers hardness in the CR and AR layers of the MCB sample during annealing at $600{ }^{\circ} \mathrm{C}$; (b) engineering stress-engineering strain curves for the $\mathrm{MCB}$ sample in the as-deformed condition and after annealing at $600{ }^{\circ} \mathrm{C}$, and for the fully recrystallized $\mathrm{AR}$ sample.

Fig.11. Stored energy calculated from the EBSD data for the deformed and recovered $\langle 111\rangle$ and $\langle 100\rangle$ regions in the $\mathrm{CR}$ and $\mathrm{AR}$ layers of the $\mathrm{MCB}$ sample in the as-deformed condition and after annealing at $600{ }^{\circ} \mathrm{C}$ for either $10 \mathrm{~min}$ or $30 \mathrm{~min}$.

Fig.12. Distributions of misorientation angles and axes for boundaries between recrystallized grains of either $\langle 111\rangle$ or $\langle 100\rangle$ texture and their surrounding non-recrystallized matrix measured in the MCB sample annealed at $600{ }^{\circ} \mathrm{C}$ for $0.5 \mathrm{~h}$ : boundaries of the $\langle 111\rangle$ grains (a) and $\langle 100\rangle$ grains (b) in the $\mathrm{CR}$ layers; boundaries of the $\langle 111\rangle$ grains (c) and $\langle 100\rangle$ grains (d) in the AR layers.

Fig. 13. The $0.2 \%$ proof stress $\left(\sigma_{0.2}\right)$ and Vickers hardness as a function of $1 / \sqrt{d}$ : (a) mechanical data for the samples studied in the present work; (b) comparison of the tensile test data for different annealed IF steel samples with similar $d$ investigated in the present experiment and in Refs.[14,15]. In 
(a) $\sigma_{0.2}$ represents the data obtained for the initial CR and AR samples and for the MCB sample in the as-deformed condition and after annealing at $600{ }^{\circ} \mathrm{C}$ for either $1 \mathrm{~h}$ or $1.5 \mathrm{~h}$. Vickers hardness was measured in the initial CR and AR samples and in the CR and AR layers of the deformed and annealed MCB samples. The dashed line in (a) is drawn between the HV data points for the initial CR and AR samples. The dashed line in (b) represents the Hall-Petch slope derived for recrystallized ARBprocessed IF steel samples which demonstrated continuous flow. Note that $d$ calculated for the annealed MCB samples based on Eq.(1) is equivalent to the average $d$ measured by the linear intercept method in more uniform microstructures of the recrystallized ARB samples.

Fig. 14. Comparison of the UTS and uniform elongation measured in the deformed and annealed MCB samples with those reported for other deformed and annealed IF steel samples. The MCB data points correspond to the conditions investigated in this experiment and to several other conditions, which were initially investigated in Ref.[13] and reanalyzed for the present work. For the literature data, the legend specifies the techniques used to deform each sample (with or without subsequent annealing).

Appendix A. Distribution of recrystallized grains in the CR and AR layers of the MCB sample annealed at $600{ }^{\circ} \mathrm{C}$ for $1 \mathrm{~h}$. The grains here are shown in random colors. The corresponding orientation map is presented in Fig.8(b). 
Click here to download high resolution image

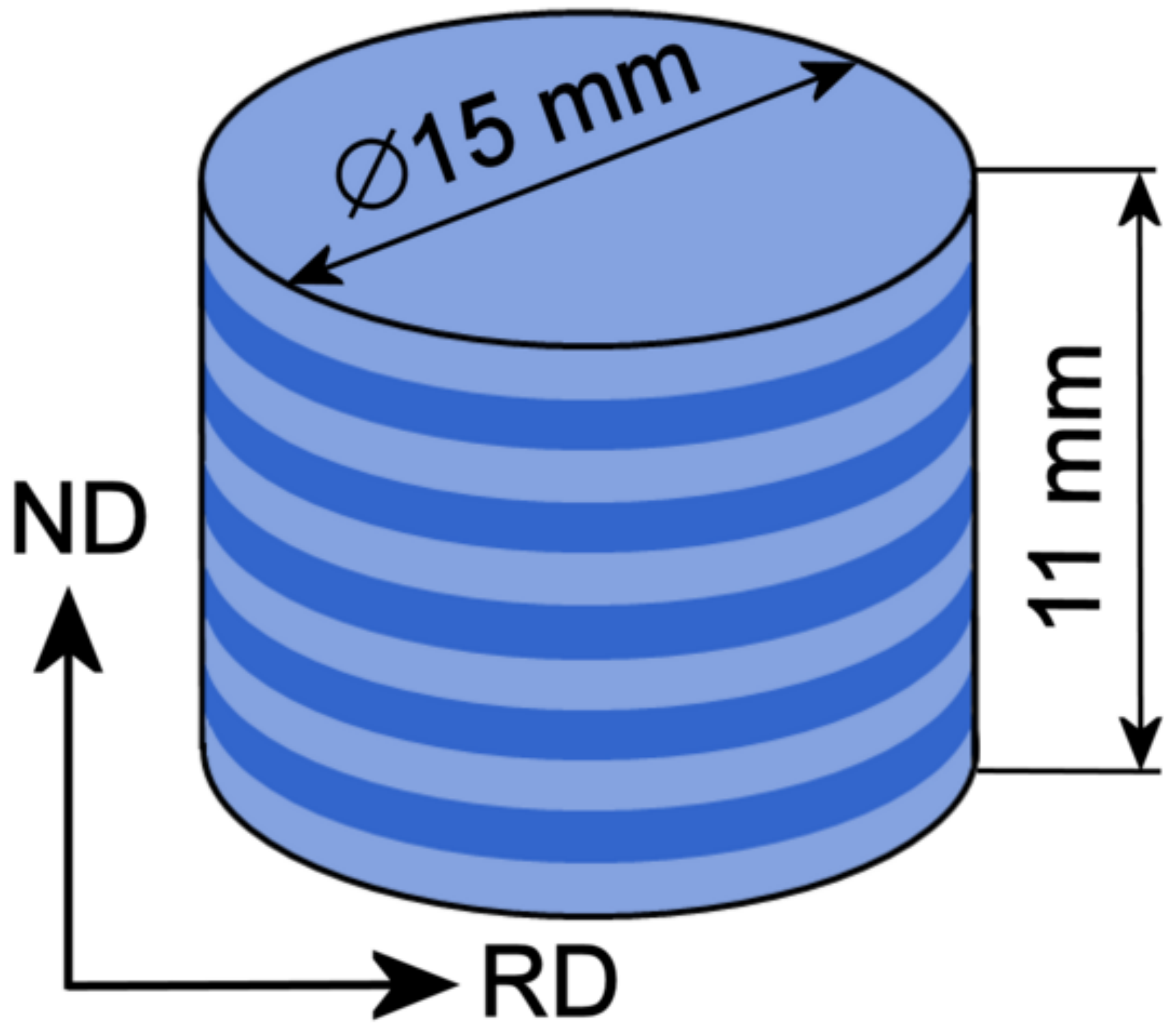


(a) astis
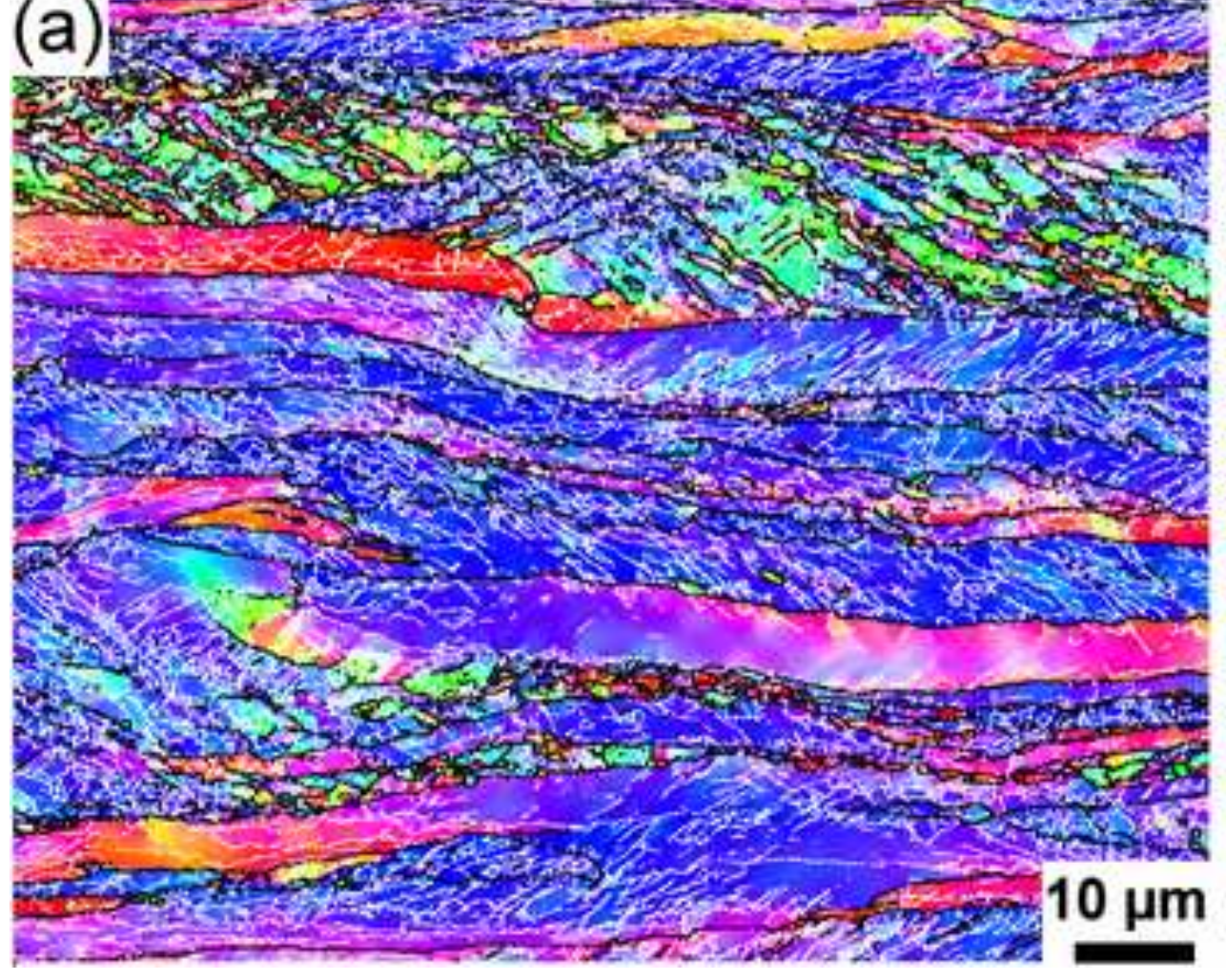

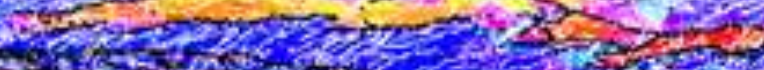

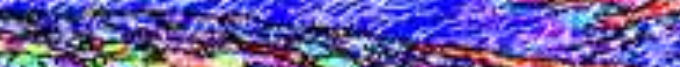

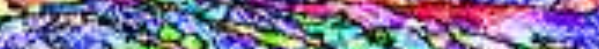

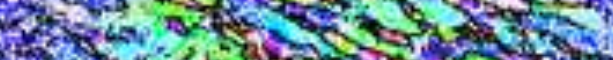

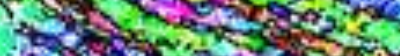

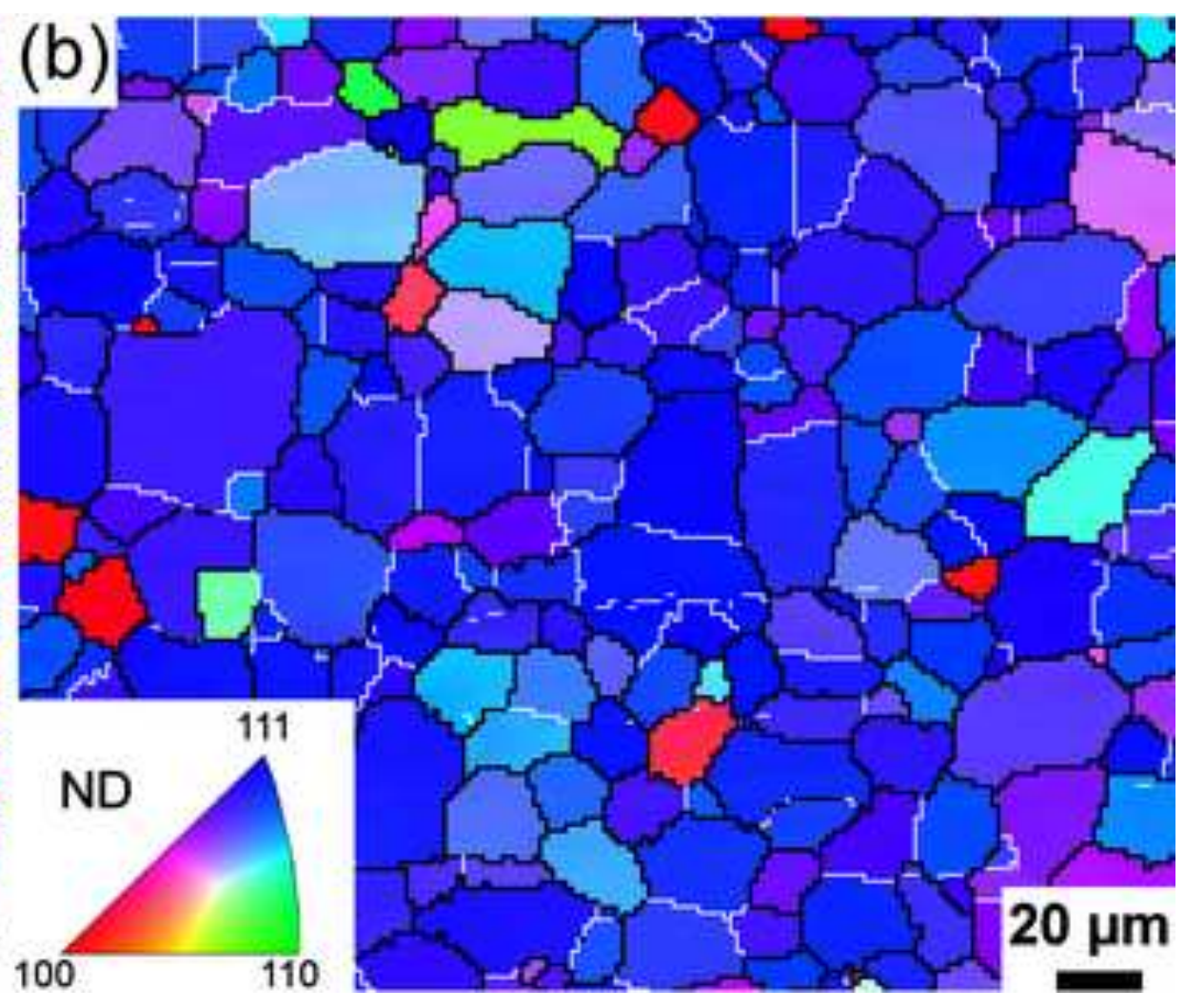


CR

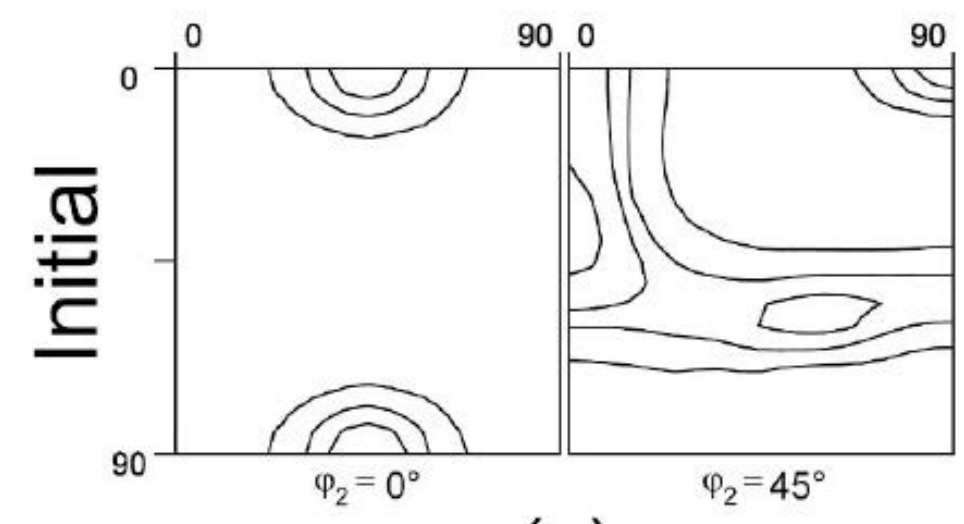

(a)

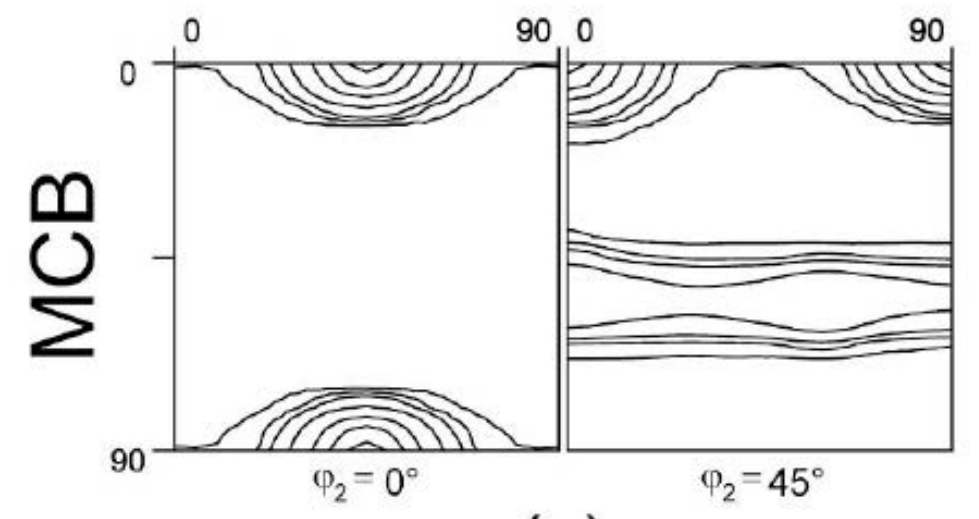

(c)
AR

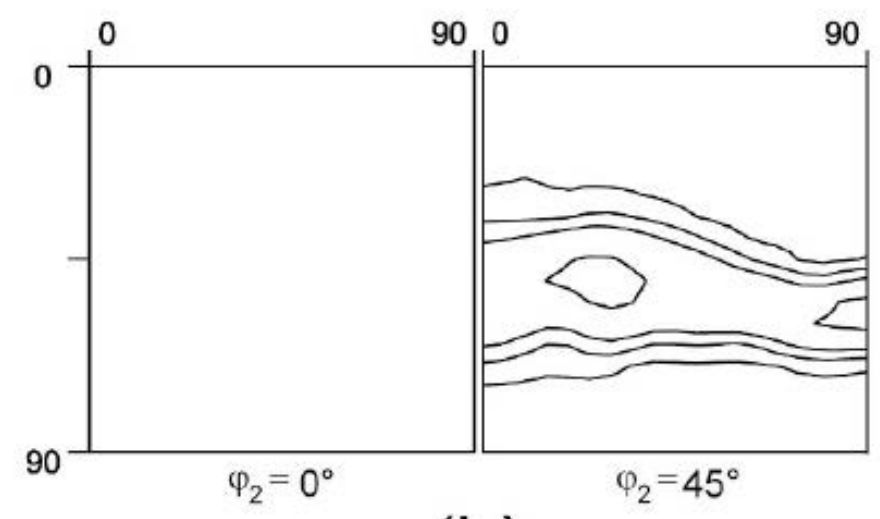

(b)

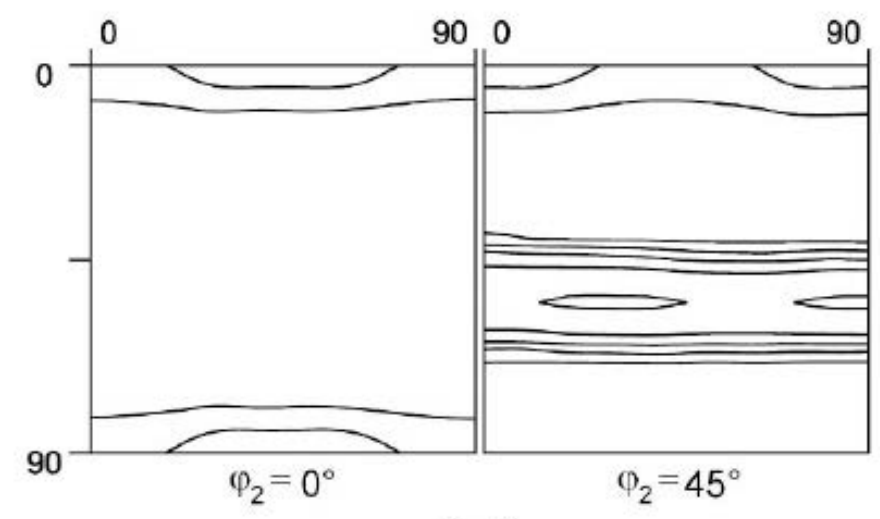

(d) 
(a) Fin

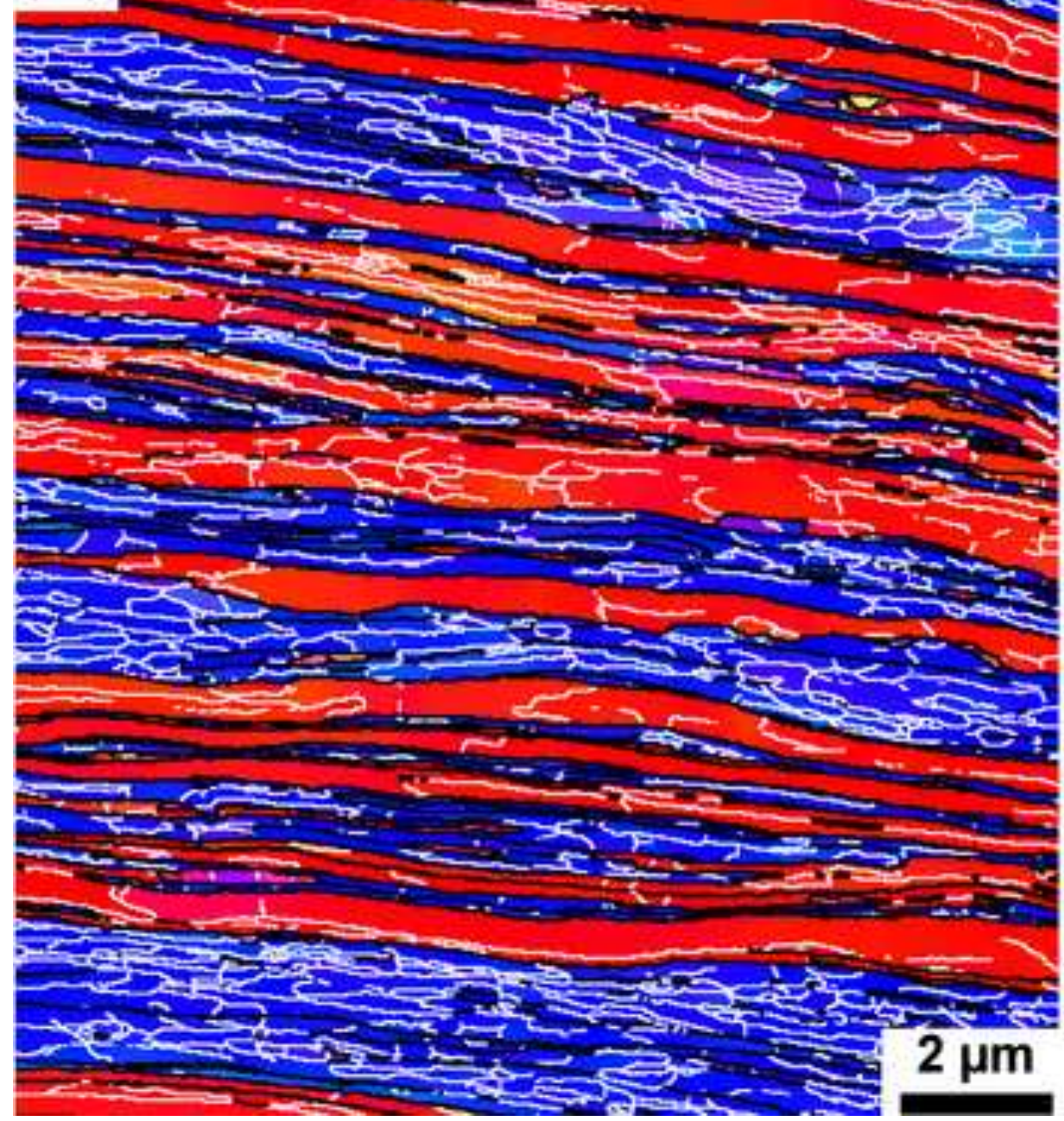

(b)

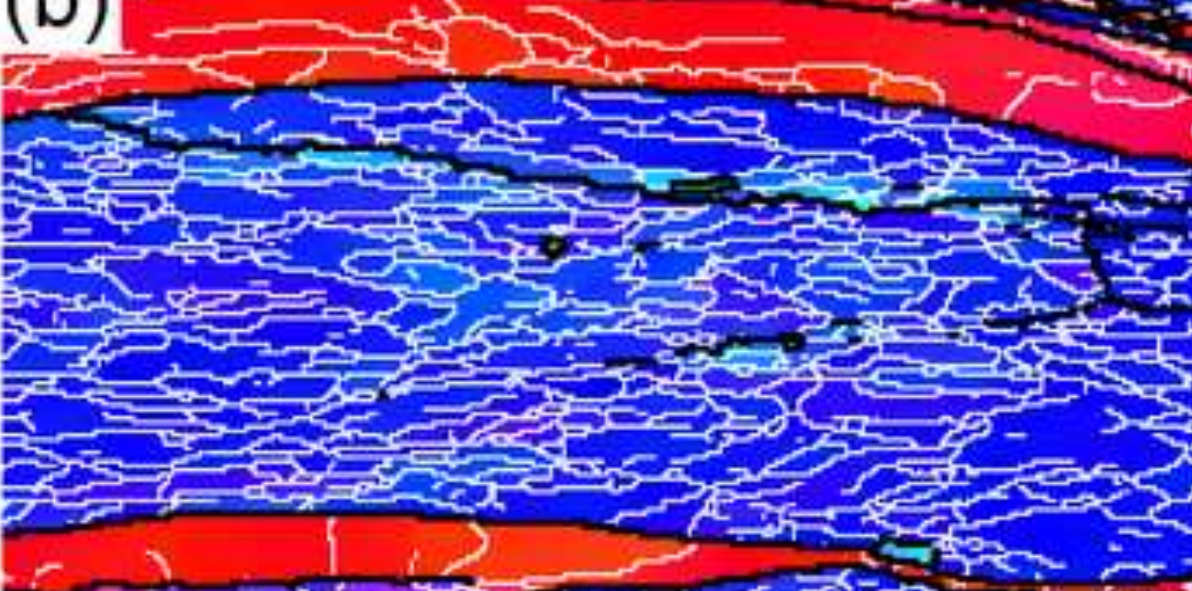
$5, \quad 1,1,2=$

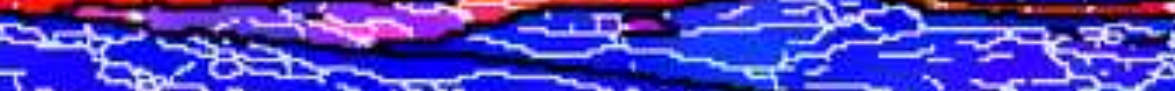

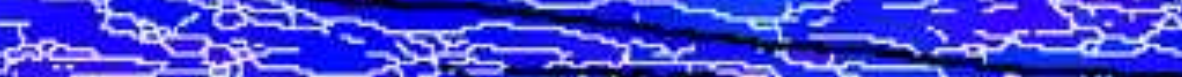

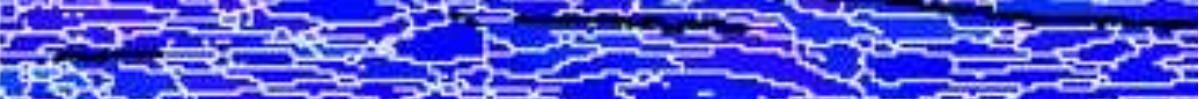

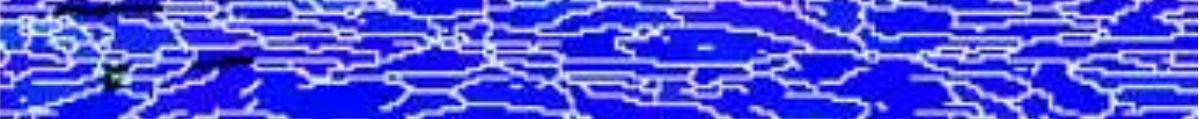

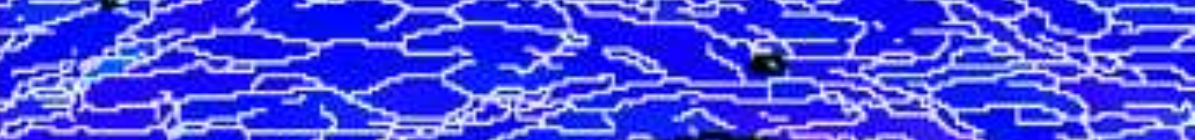

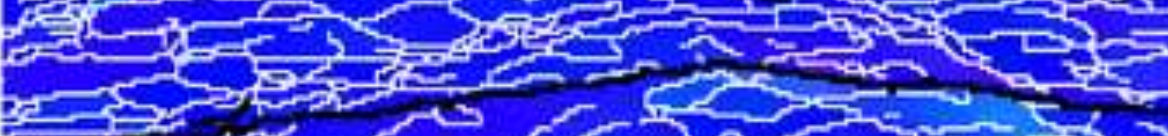

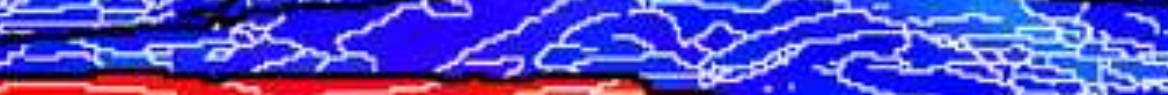
5 , 
Click here to download high resolution image

(a)

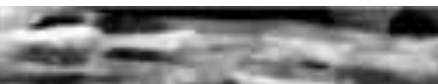

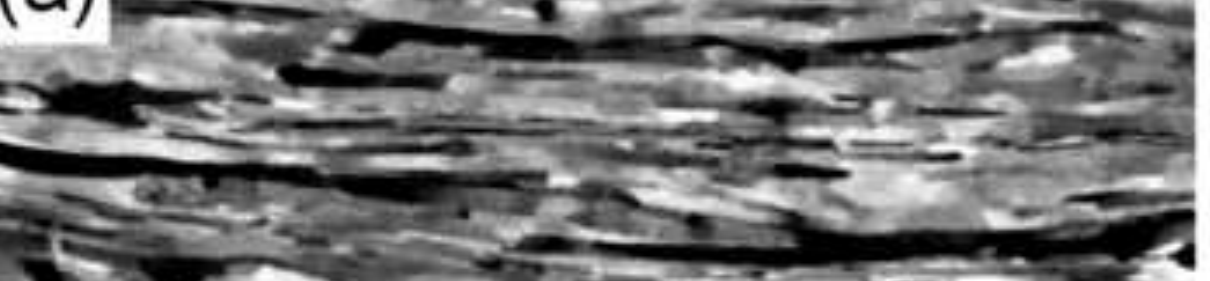
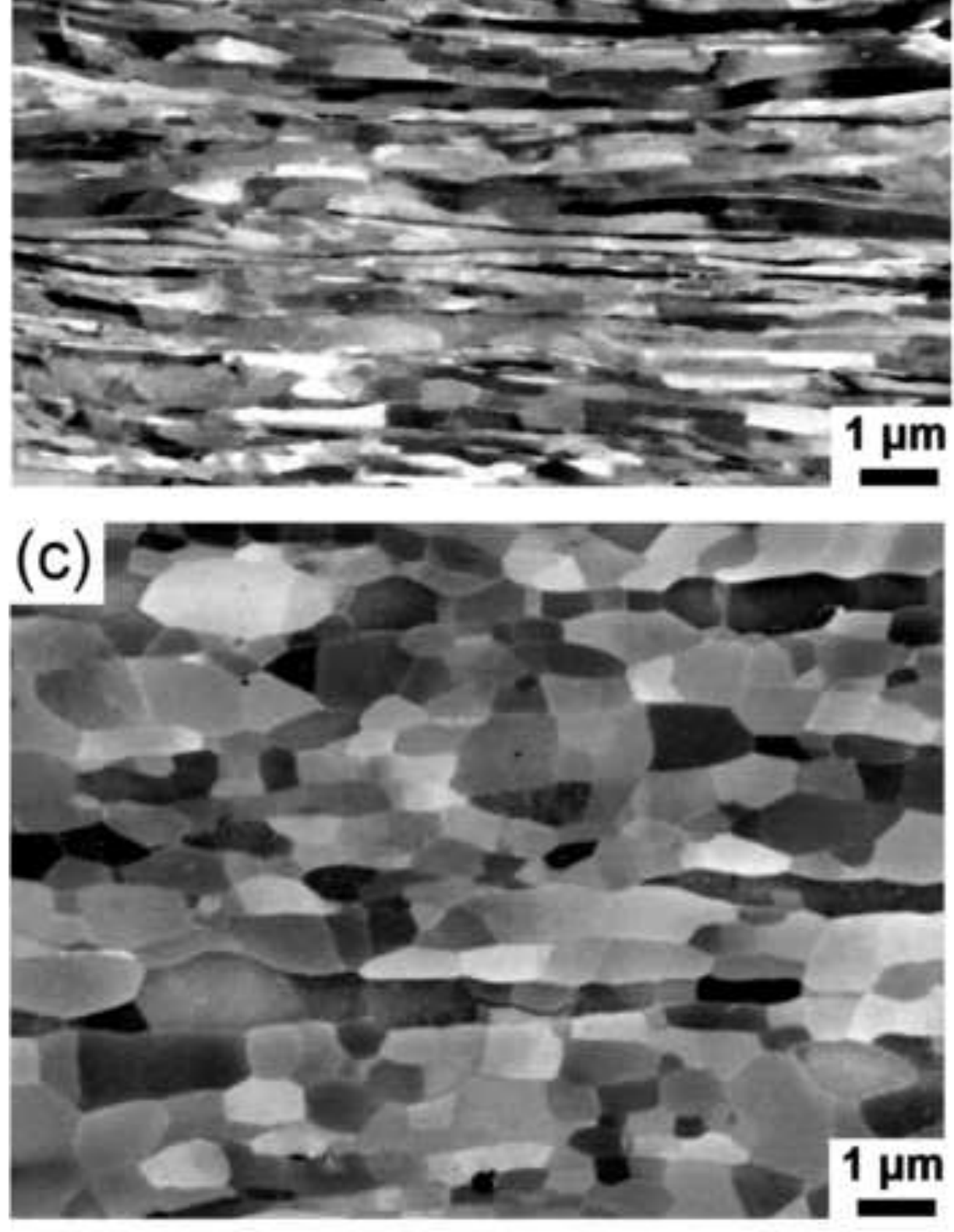

(b) -
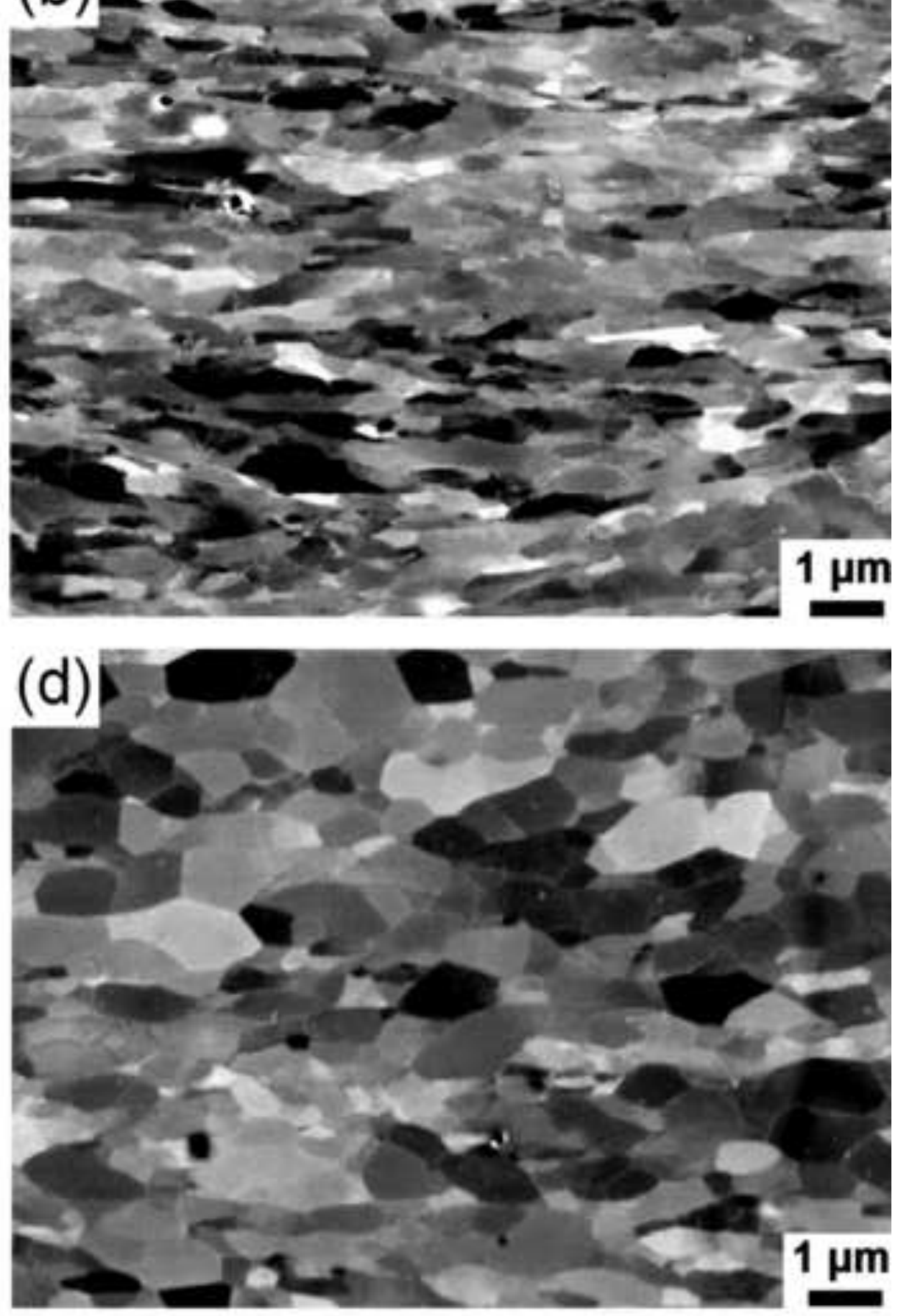

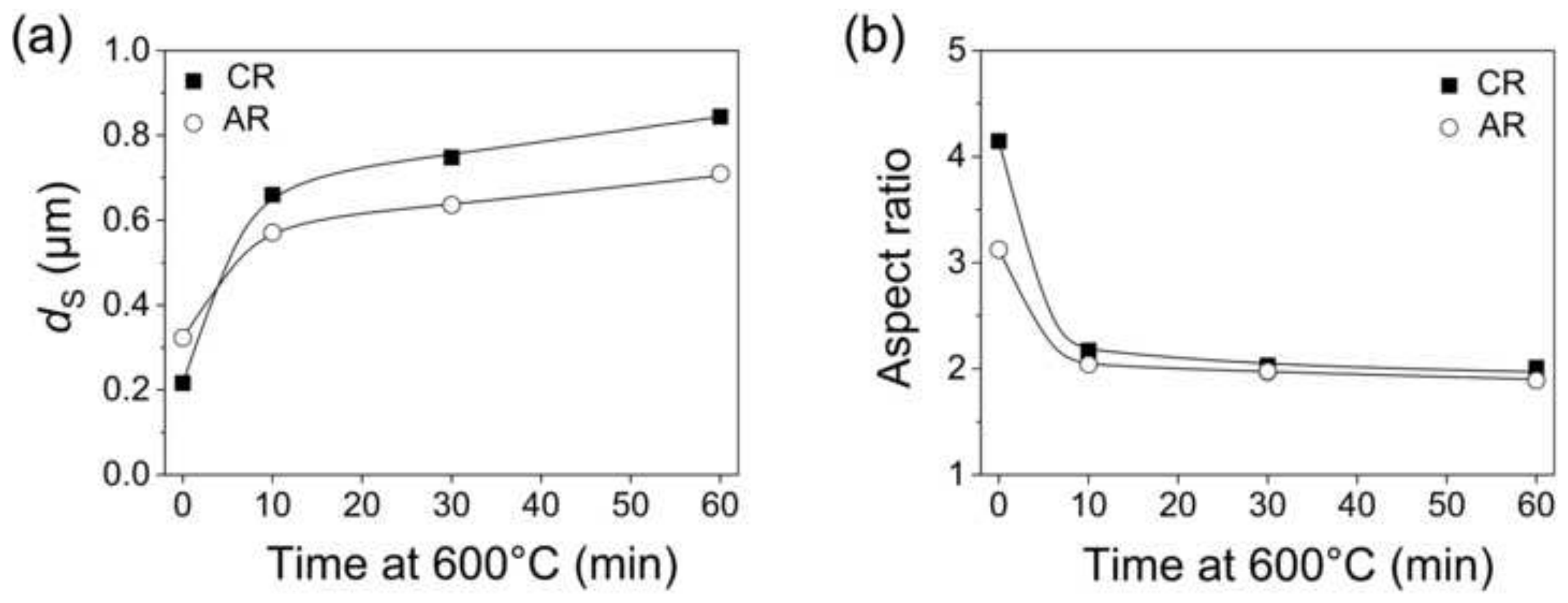
(a)

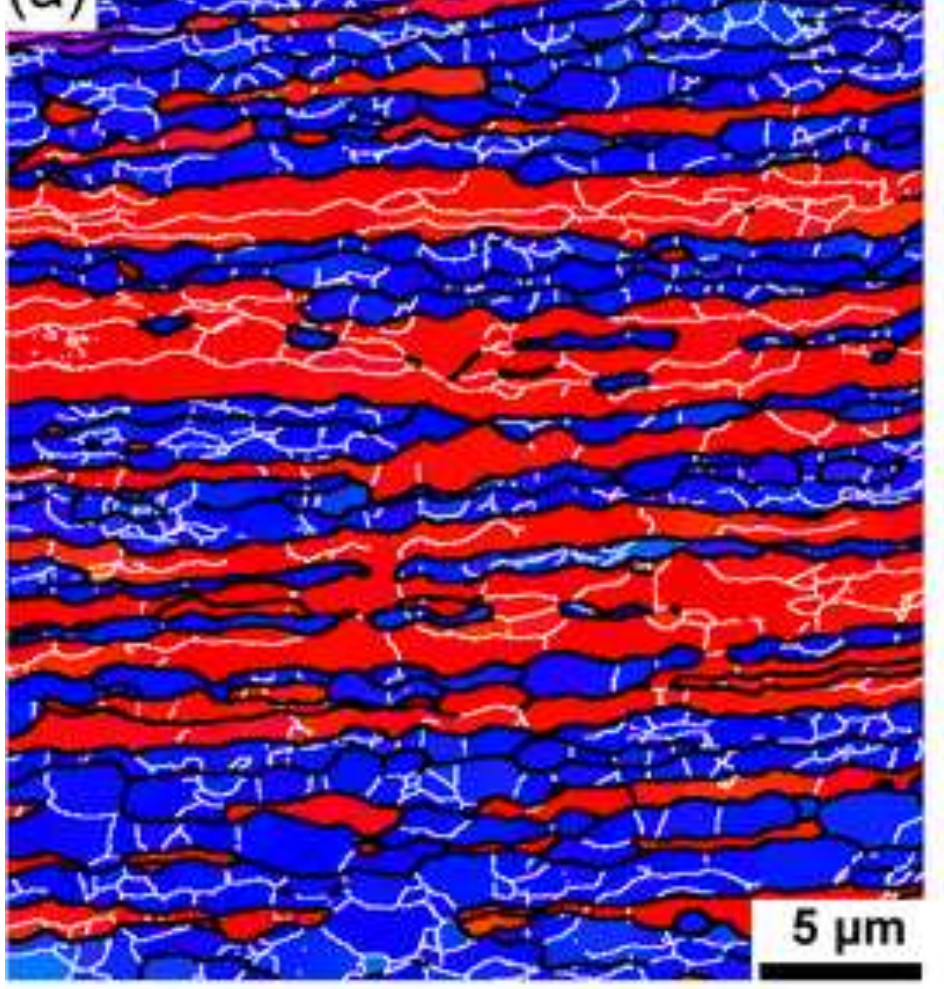

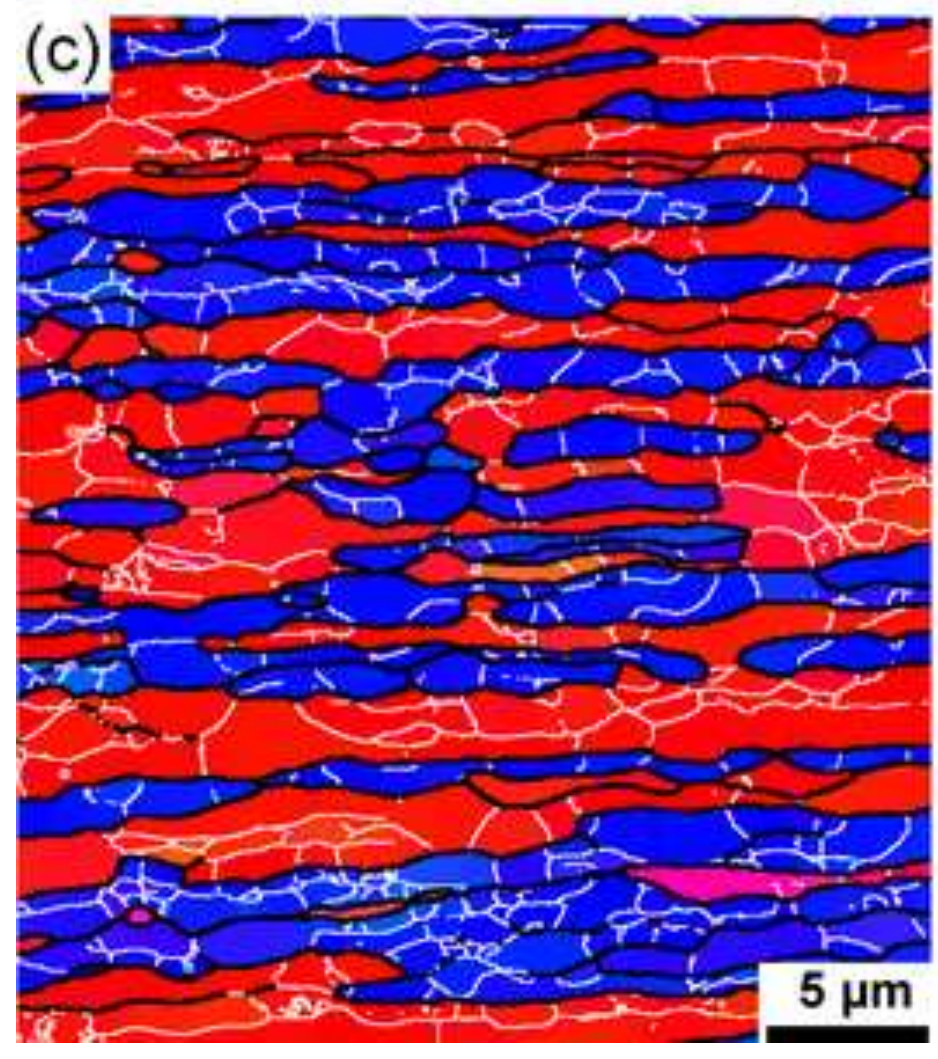

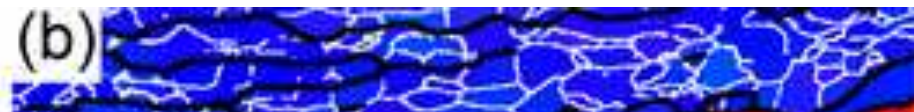

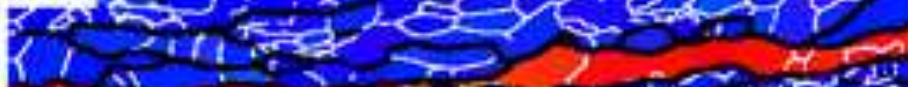
Na" in

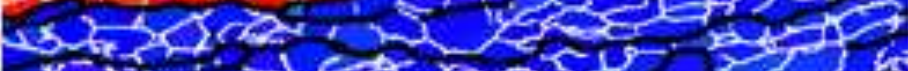
$x \rightarrow y=0$.

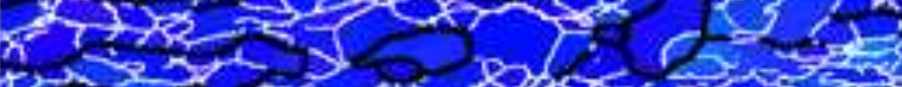

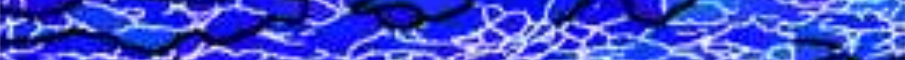

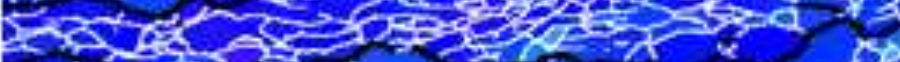
है

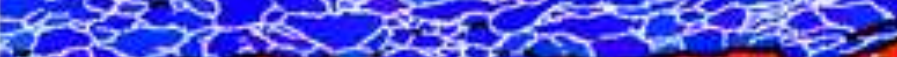

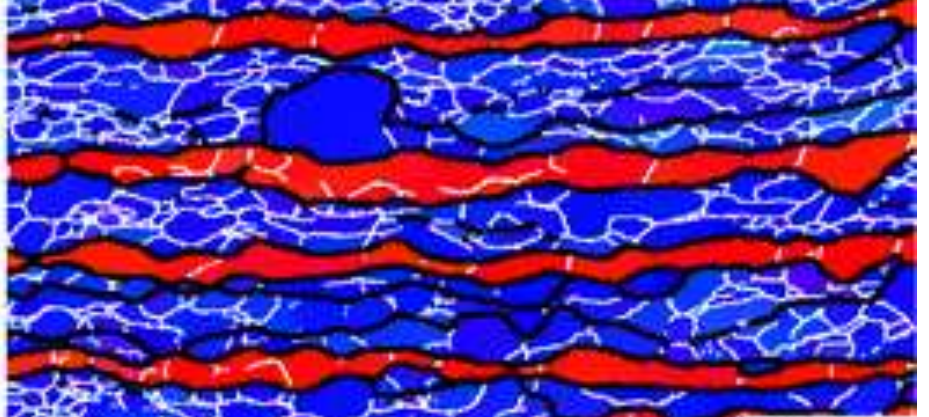
क्या

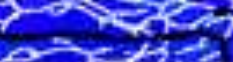
ax

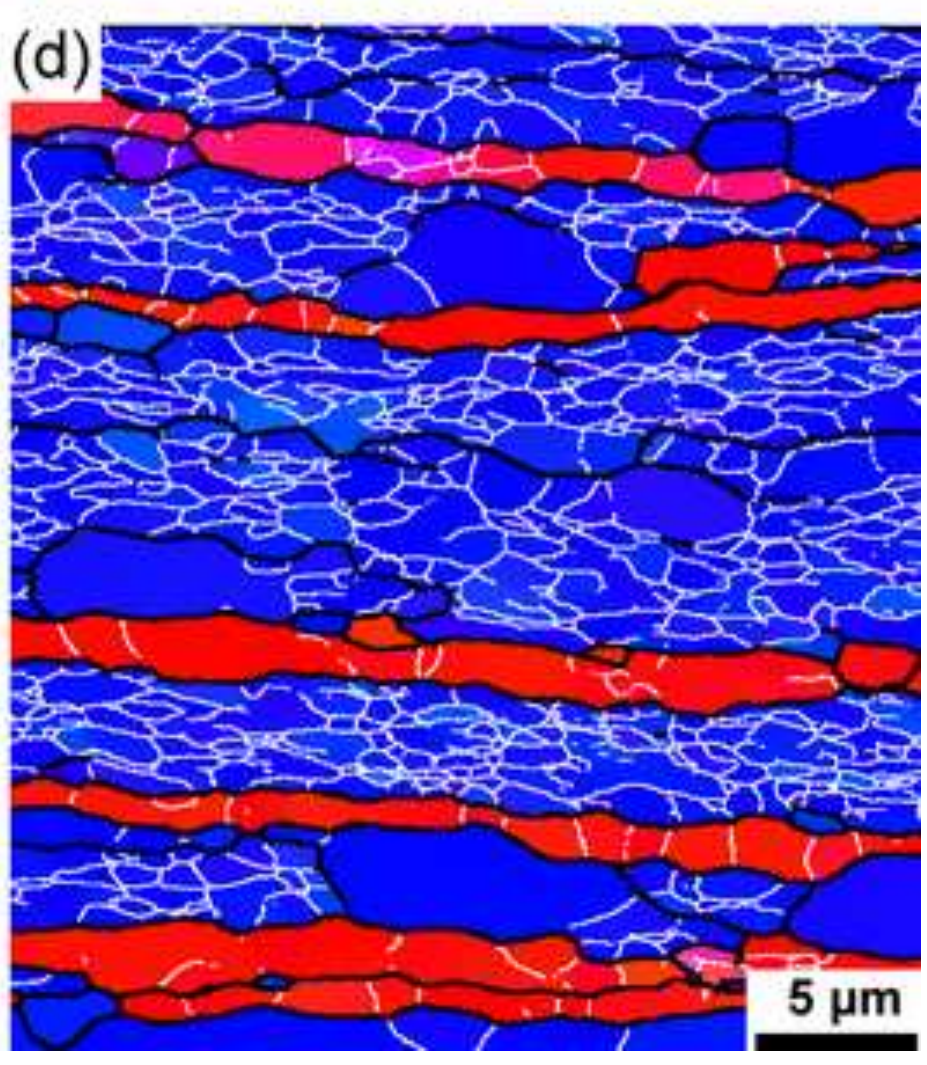




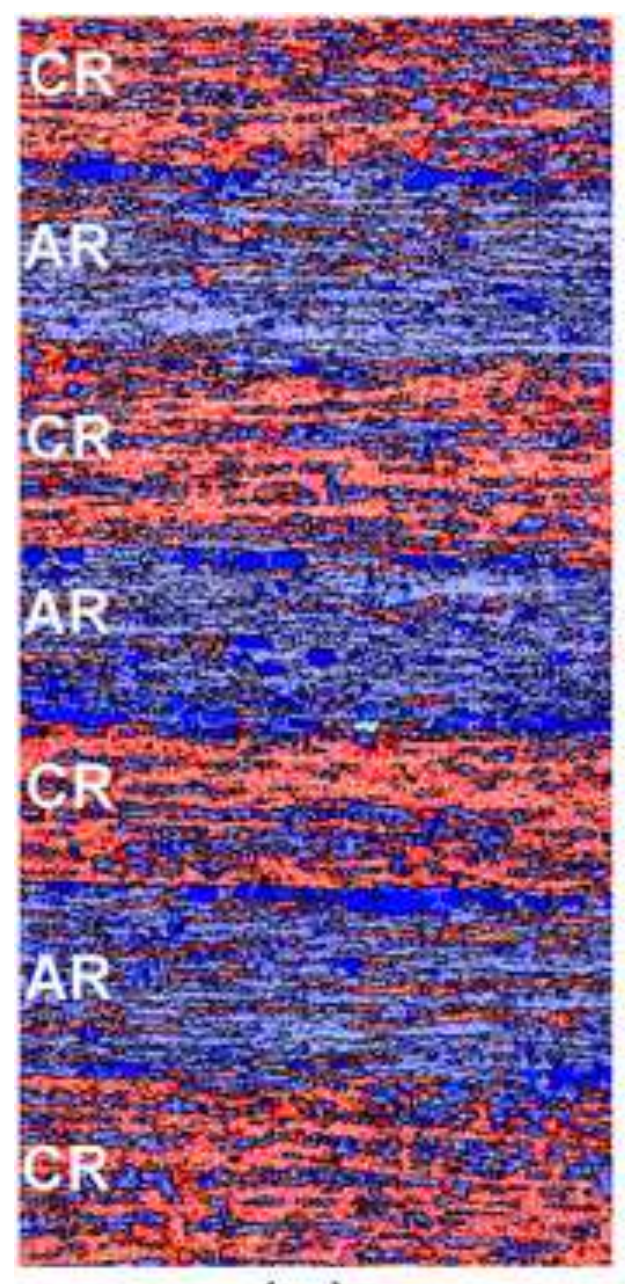

(a)

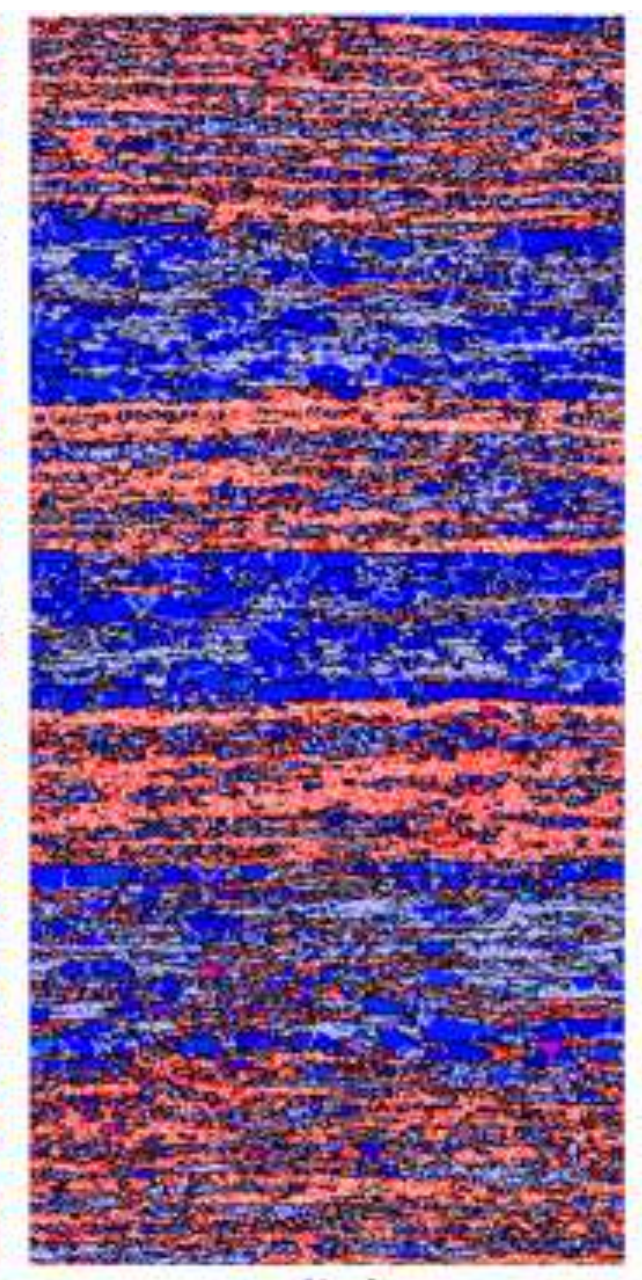

(b)

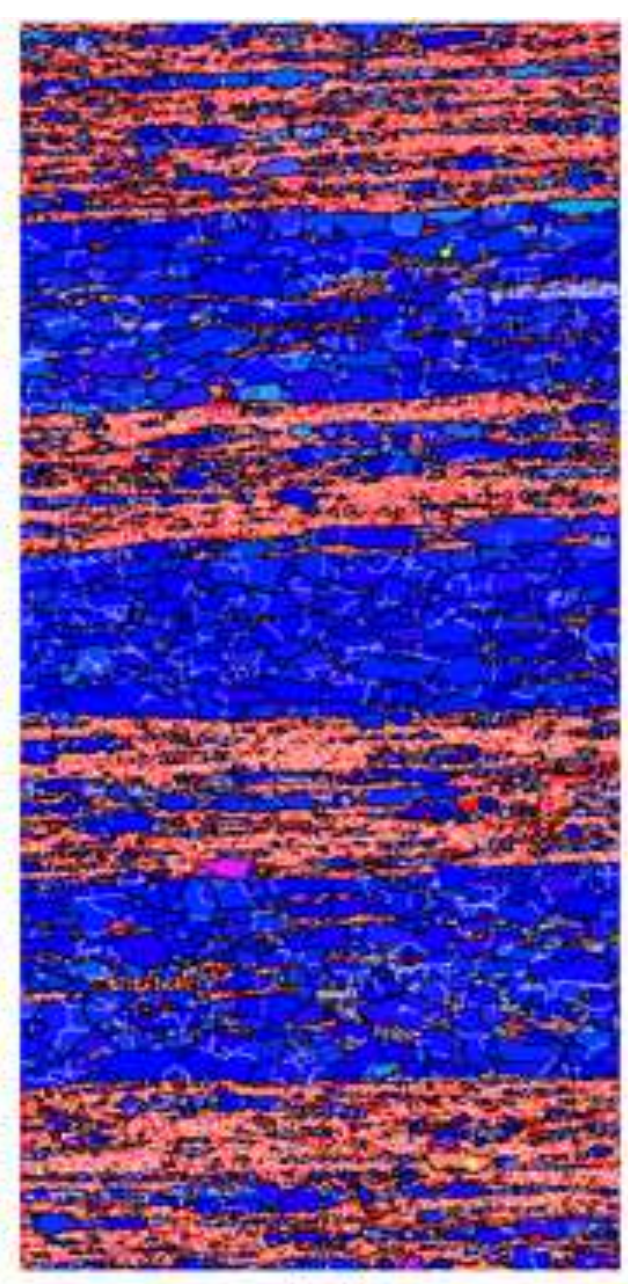

(c)

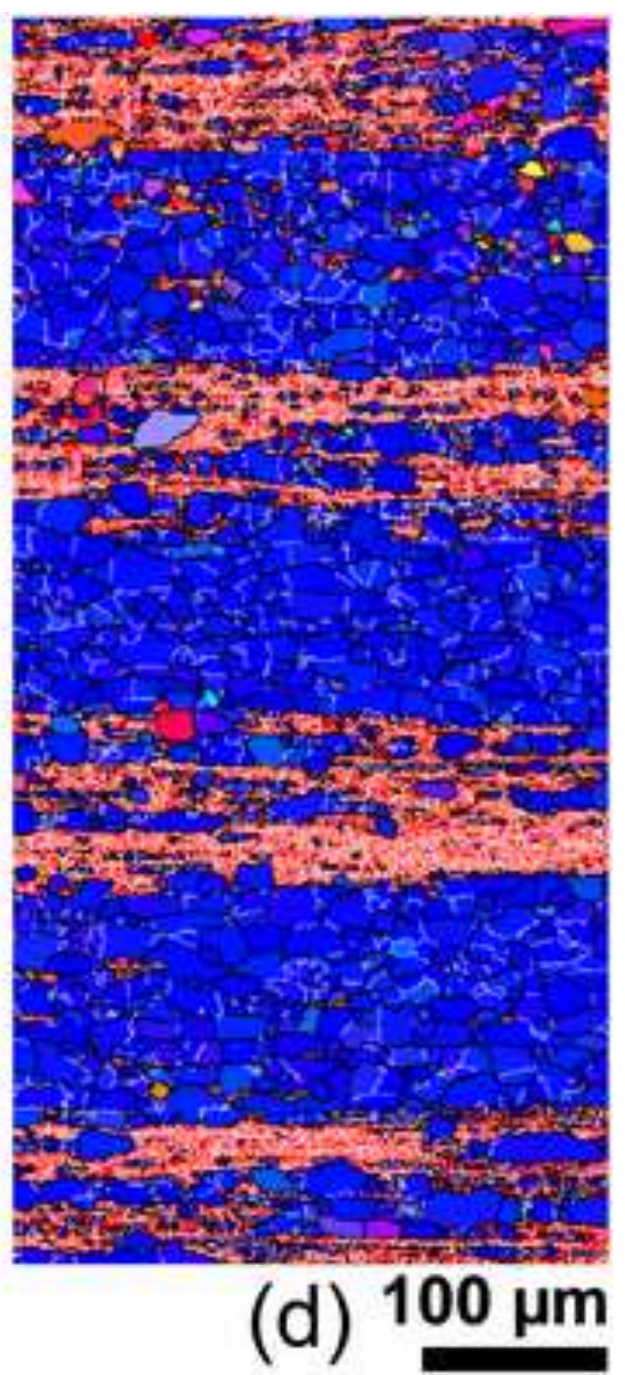



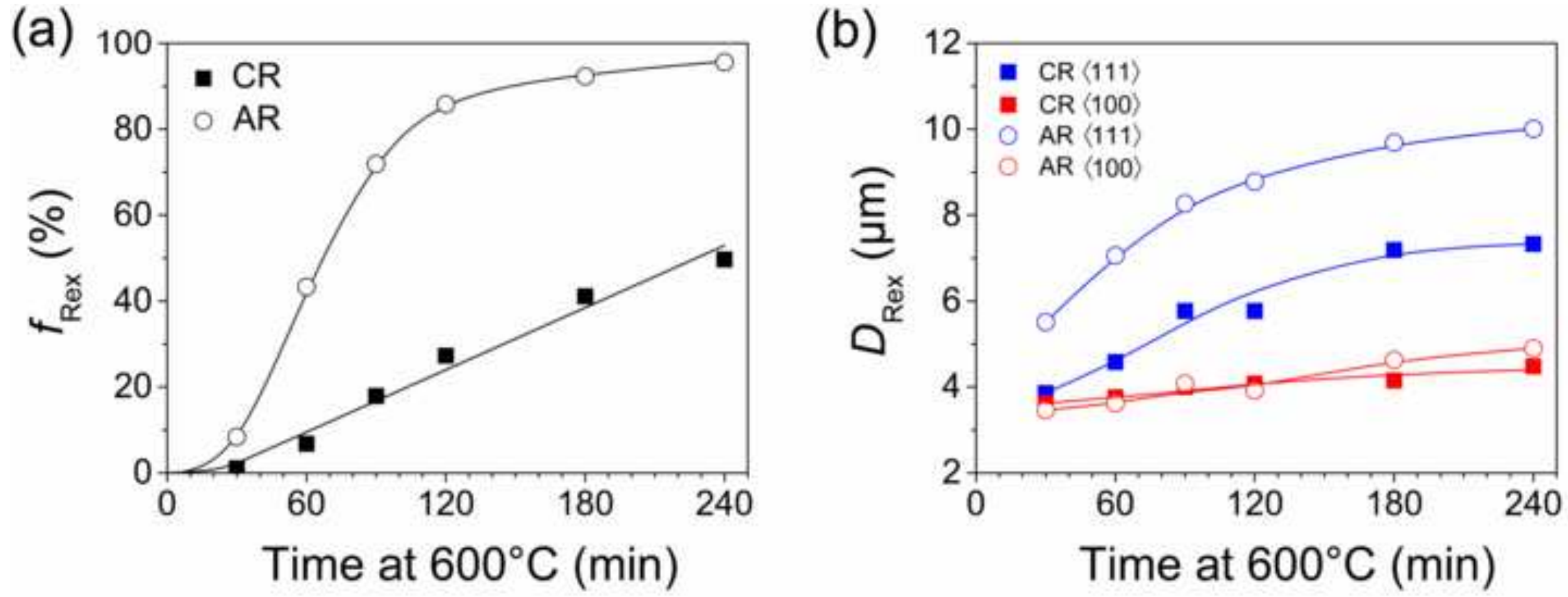


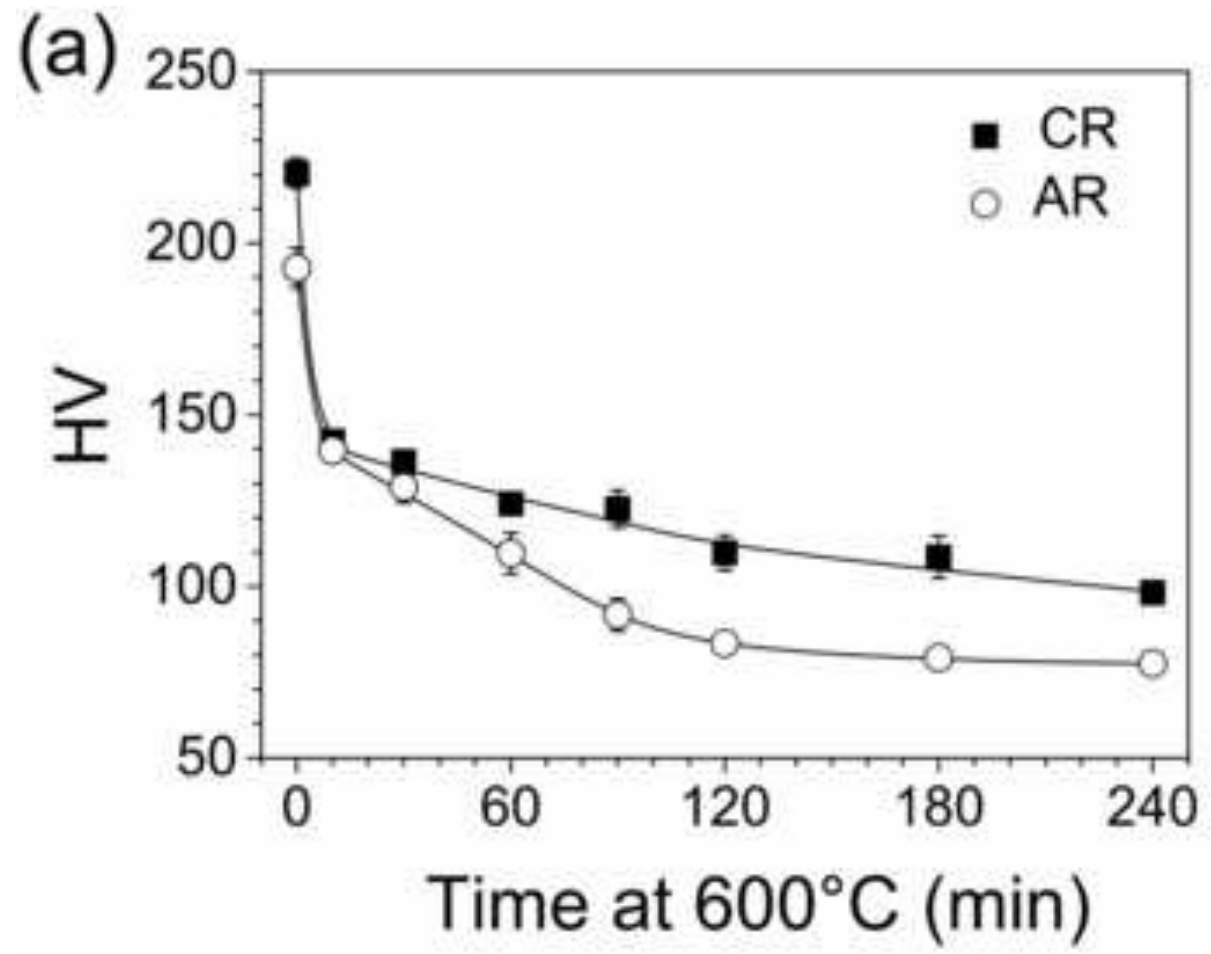

(b)

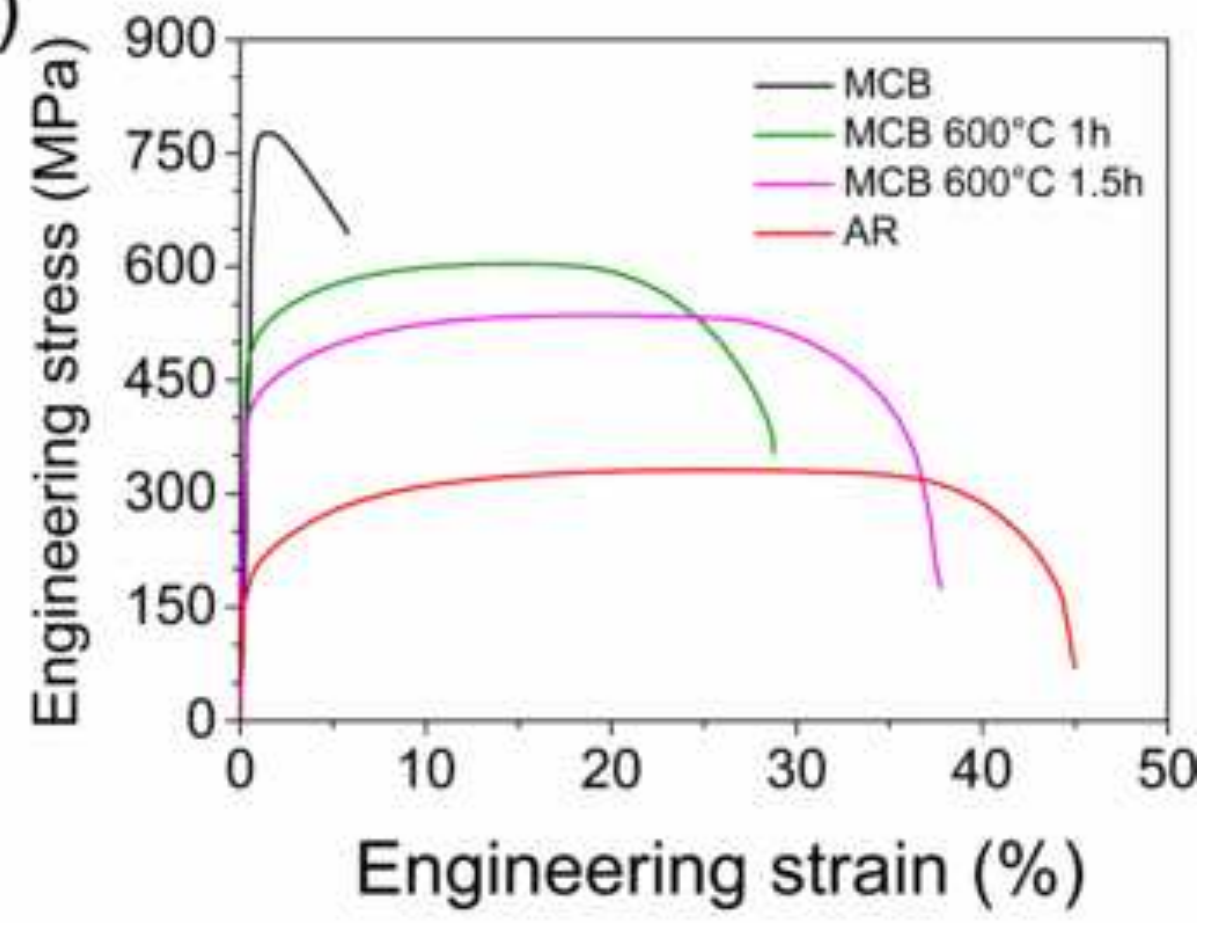


Click here to download high resolution image

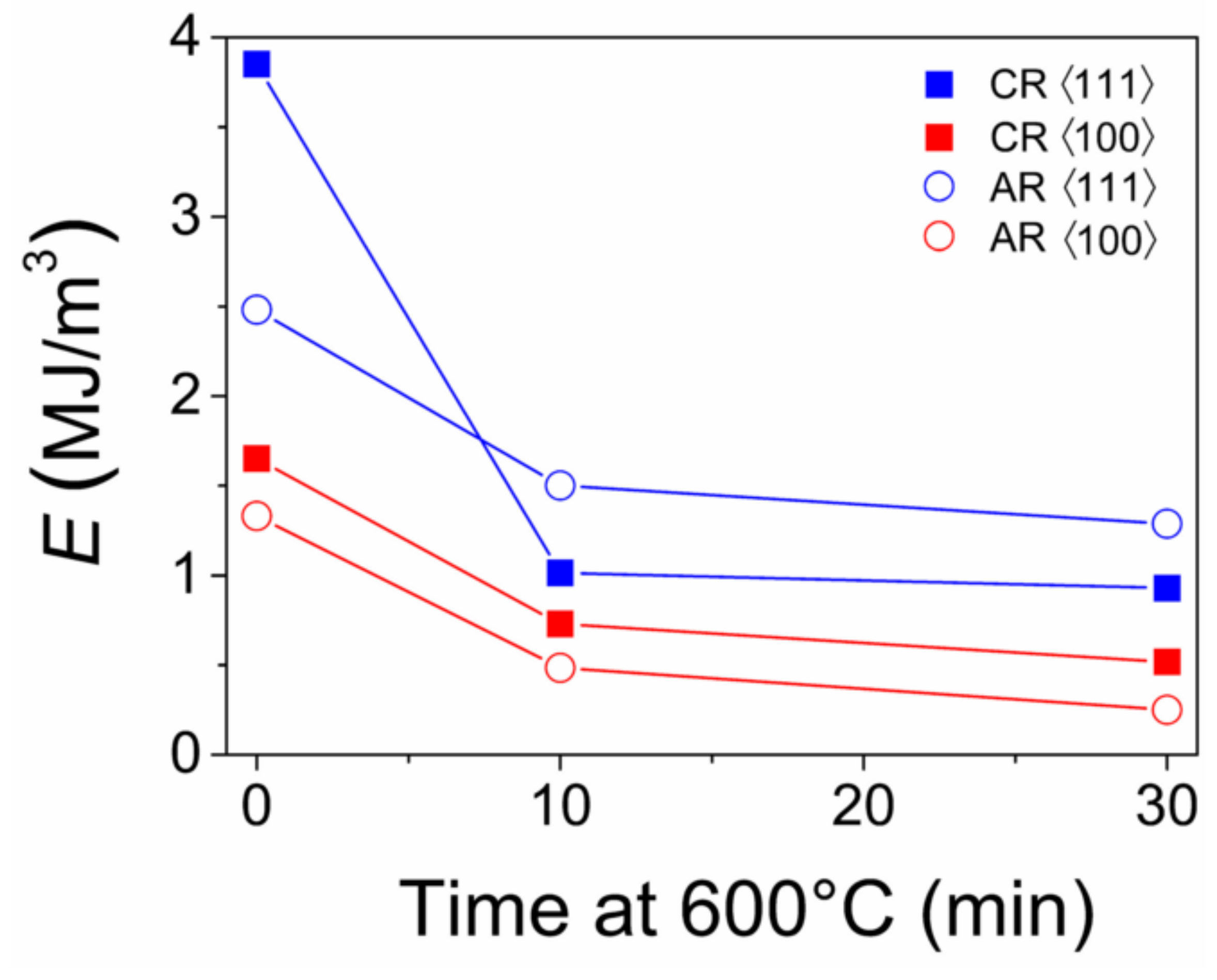



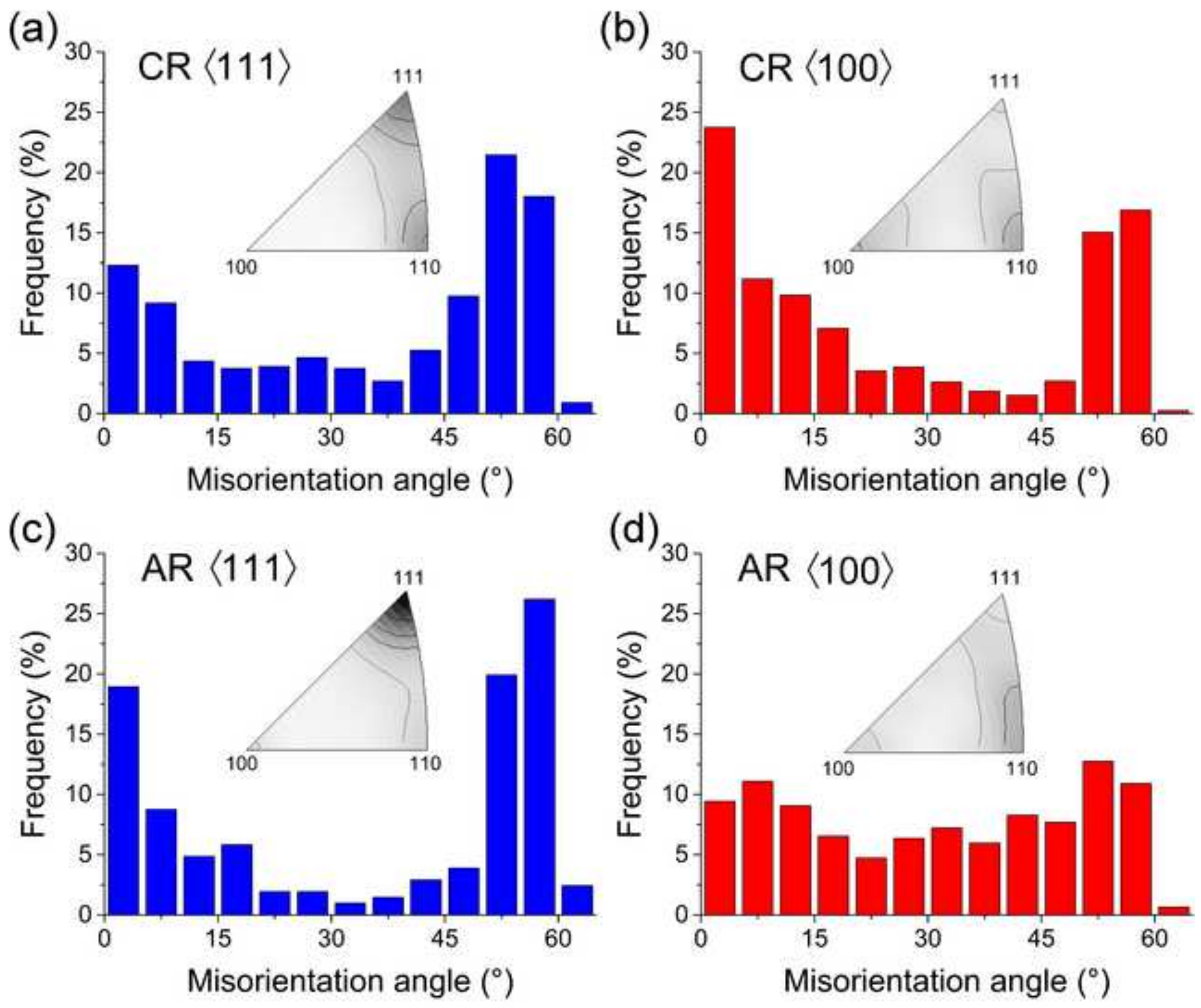


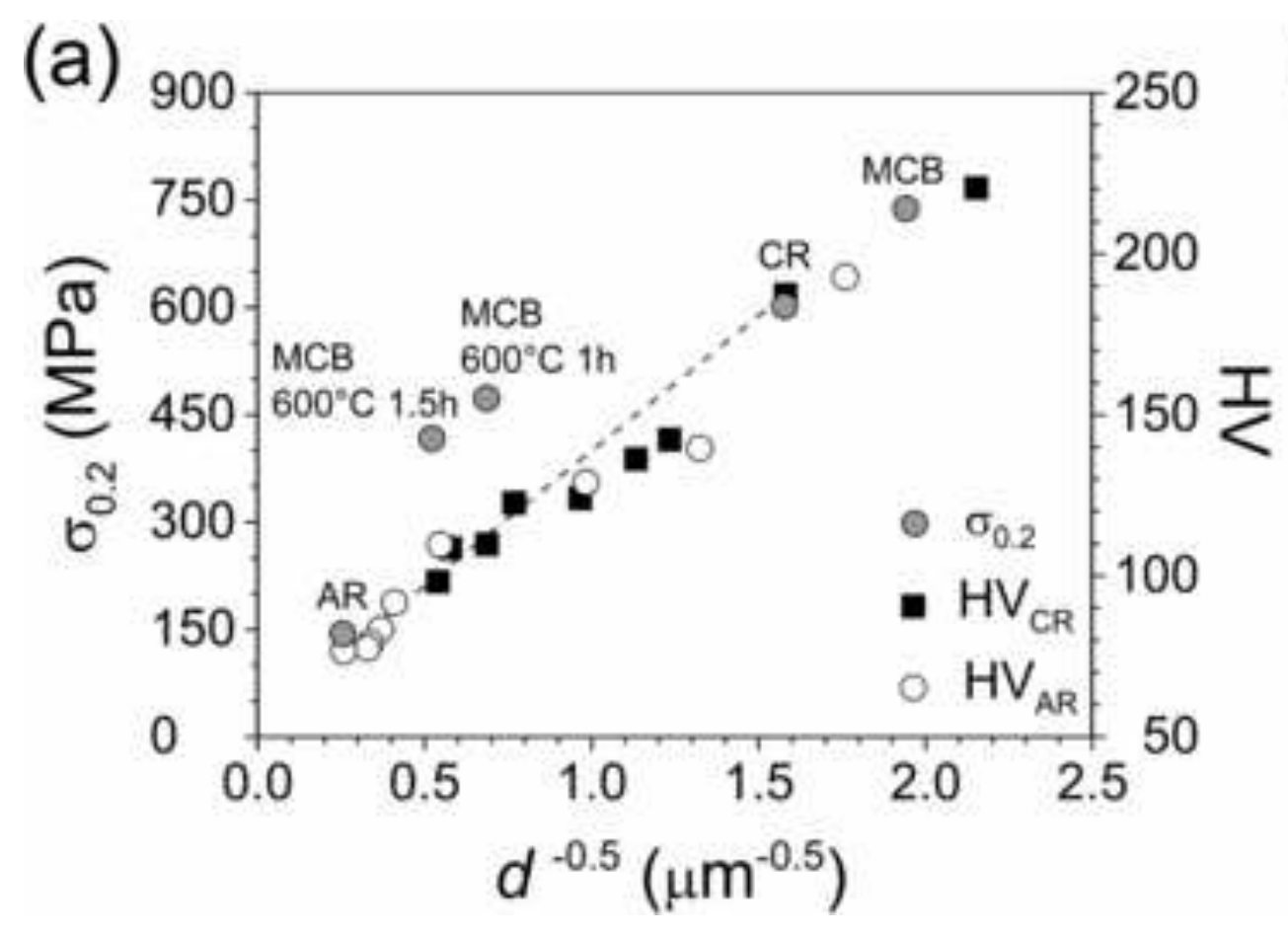

(b)

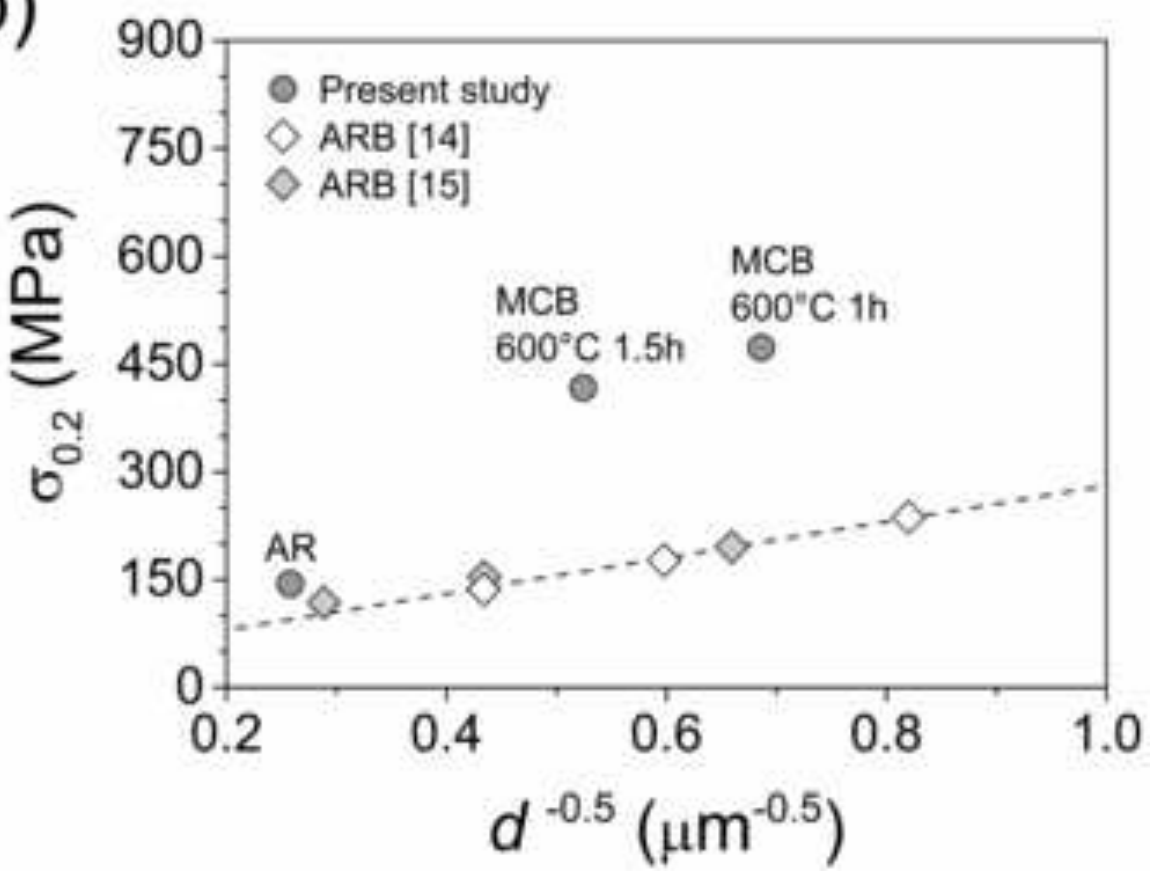




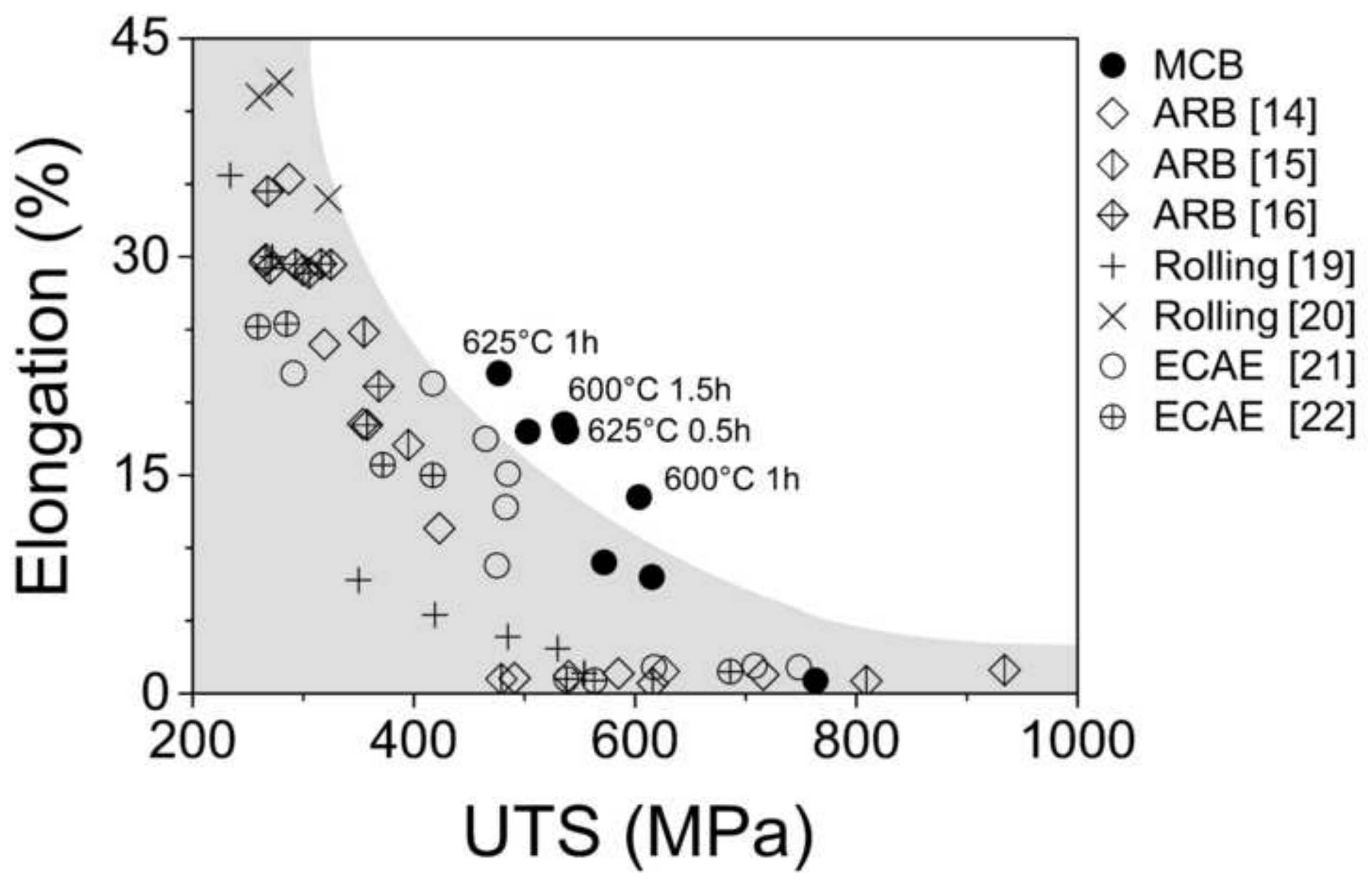




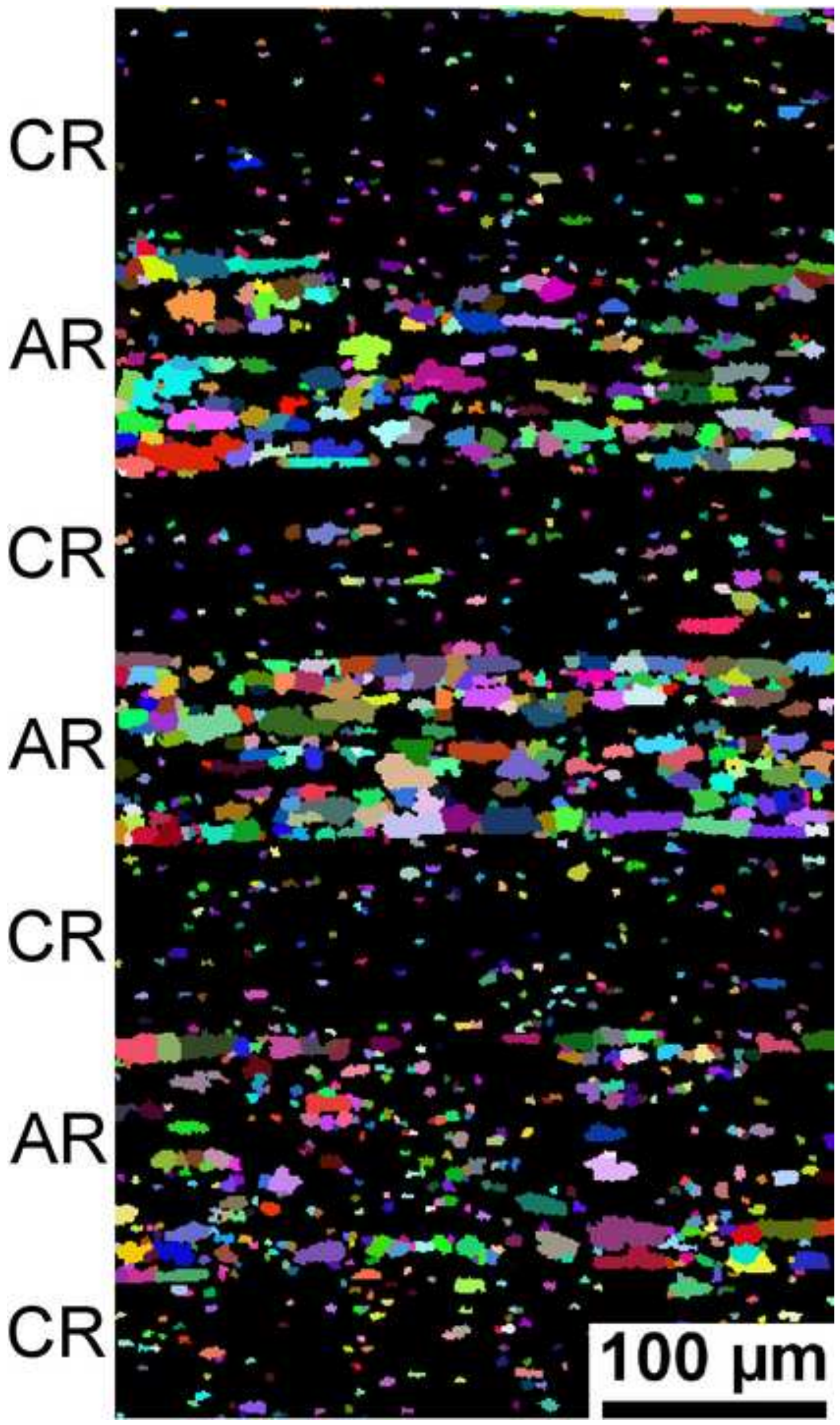

